\title{
Non-invasive delivery strategies for biologics
}

\begin{abstract}
Aaron C. Anselmo', Yatin Gokarn'² and Samir Mitragotri3*
Abstract | Biologics now constitute a significant element of available medical treatments. Owing to their clinical and commercial success, biologics are a rapidly growing class and have become a dominant therapeutic modality. Although most of the successful biologics to date are drugs that bear a peptidic backbone, ranging from small peptides to monoclonal antibodies ( $\sim 50$ residues; $150 \mathrm{kDa}$ ), new biologic modalities, such as nucleotide-based therapeutics and viral gene therapies, are rapidly maturing towards widespread clinical use. Given the rise of peptides and proteins in the pharmaceutical landscape, tremendous research and development interest exists in developing less-invasive or non-invasive routes for the systemic delivery of biologics, including subcutaneous, transdermal, oral, inhalation, nasal and buccal routes. This Review summarizes the current status, latest updates and future prospects for such delivery of peptides, proteins and other biologics.
\end{abstract}

Proteins and peptides now constitute a major proportion of therapeutic modalities being pursued for the treatment of various diseases ${ }^{1}$. Nearly $30 \%$ of all drugs approved by the US Food and Drug Administration (FDA) in 2015-2018 were biologics, which, for the purpose of this article, are defined as oligomeric or polymeric molecules with peptidic backbones. Over 60 peptides are currently approved by the FDA for various indications, and at least twice that many are in clinical trials ${ }^{2}$. Monoclonal antibodies (mAbs) have emerged as the dominant therapeutic modality, with over 50 approved products ${ }^{3}$ and over $500 \mathrm{mAb}$-based therapies in clinical development. Of the recently approved biologics, greater than $90 \%$ were $\mathrm{mAb}$-based drugs. This increasing success of biologics can be attributed to their favourable safety, target specificity and pharmacokinetics compared with traditional small-molecule drugs.

A direct consequence of this success is that biologicsbased medicines are causing a fundamental transformation in how drugs are administered to patients. Small-molecule drugs, which are predominantly delivered orally, are increasingly being replaced by biologics, which necessitate delivery via parenteral routes. Oral delivery of medicine is convenient and well-accepted and has enabled patient compliance ${ }^{4}$. Biologics, on the other hand, require invasive injections because of their poor bioavailability via the oral route. Biologics are highly susceptible to degradation in the alimentary canal, and their relatively large size limits transport across the epithelium ${ }^{5}$. Transport challenges associated with intestinal biology generally apply to other biological barriers such as the skin and mucus. Another critical factor is that biologic drugs span a tremendously wide therapeutic dose range, from ng per kg (agonists) to $\mathrm{mg}$ per kg (antagonists), which can guide the drug delivery strategy to accommodate the size or the molecular mass of the biologic coupled with the intended dose.

Finding administration routes that are patientfriendly and identifying those that can be used over broad dose ranges are two of the most important disruptions that can be achieved through the development of strategies and technologies for the delivery of biologics. As such, academic and industrial efforts are focused on developing novel approaches for the delivery of biologics for systemic absorption. These approaches focus on converting intravenous administration to either more convenient subcutaneous injections or noninvasive routes, such as transdermal, oral, buccal, nasal or inhalation routes. Strategies for overcoming delivery barriers to the systemic delivery of biologics have to consider the specific barrier challenges that are dependent on the delivery route, the potential advantages of the delivery route (TABLE 1), the intended dose and frequency of dosing, and the molecular complexity of the biologic. Diffusion to blood vessels is a common limiting factor for all non-invasive delivery routes, and this is likely to disproportionately affect larger and higher-dose biologics, especially in the crowded in vivo environment (BOX 1). To date, a number of non-invasive strategies have successfully navigated these barriers and have been approved for the delivery of biologics in the clinic. These successes have laid the foundations for the next iteration 
Table 1 | Overview of administration routes

\begin{tabular}{|c|c|c|c|c|}
\hline $\begin{array}{l}\text { Route } \\
\text { (absorption site) }\end{array}$ & Advantages & Disadvantages & $\begin{array}{l}\text { Barrier properties and } \\
\text { delivery challenges }\end{array}$ & $\begin{array}{l}\text { Example biologic } \\
\text { (delivery system) }\end{array}$ \\
\hline Intravenous & $\begin{array}{l}\text { - } 100 \% \text { bioavailability } \\
\text { - Reproducibility }\end{array}$ & $\begin{array}{l}\text { - Painful injection } \\
\text { - Requires medical } \\
\text { personnel }\end{array}$ & None & $\begin{array}{l}\text { Numerous peptides, antibodies } \\
\text { and cell therapies have been } \\
\text { approved and are used clinically }\end{array}$ \\
\hline Subcutaneous & $\begin{array}{l}\text { - Can be self-administered } \\
\text { - Avoids first-pass metabolism }\end{array}$ & Painful injection & $\begin{array}{l}\text { - Extracellular matrix } \\
\text { - Limited space for injectable } \\
\text { volumes }\end{array}$ & $\begin{array}{l}\text { Numerous proteins and } \\
\text { antibodies (hyaluronidase-based } \\
\text { enhancers) }\end{array}$ \\
\hline Oral (intestines) & $\begin{array}{l}\text { - Non-invasive } \\
\text { - Can be self-administered }\end{array}$ & $\begin{array}{l}\text { - Harsh chemical } \\
\text { environment } \\
\text { - Degraded by first-pass } \\
\text { metabolism }\end{array}$ & $\begin{array}{l}\text { - Epithelial cells } \\
\text { - Mucus } \\
\text { - Bacteria } \\
\text { - Gastrointestinal transit } \\
\text { time } \\
\text { - Acid, enzymes and } \\
\text { proteases }\end{array}$ & $\begin{array}{l}\text { Insulin (capsules with enzyme } \\
\text { inhibitors and/or permeation } \\
\text { enhancers) }\end{array}$ \\
\hline $\begin{array}{l}\text { Buccal (oral } \\
\text { mucosal surface) }\end{array}$ & $\begin{array}{l}\text { - Non-invasive } \\
\text { - Can be self-administered } \\
\text { - Rapid absorption } \\
\text { - Avoids first-pass metabolism }\end{array}$ & $\begin{array}{l}\text { - Low surface area for } \\
\text { absorption, which limits } \\
\text { total dose } \\
\text { - Prone to irritation }\end{array}$ & $\begin{array}{l}\text { - Mucus } \\
\text { - Epithelial cells }\end{array}$ & Insulin (buccal films) \\
\hline $\begin{array}{l}\text { Nasal (nasal } \\
\text { mucosal surface) }\end{array}$ & $\begin{array}{l}\text { - Non-invasive } \\
\text { - Can be self-administered } \\
\text { - Rapid absorption } \\
\text { - Avoids first-pass metabolism }\end{array}$ & $\begin{array}{l}\text { - Low surface area for } \\
\text { absorption, which limits } \\
\text { total dose } \\
\text { - Prone to irritation }\end{array}$ & $\begin{array}{l}\text { - Mucus } \\
\text { - Epithelial cells }\end{array}$ & Numerous vaccines (nasal sprays) \\
\hline
\end{tabular}

of non-invasive delivery technologies for biologics, many of which are being translated into the clinic in small, as well as large, biopharmaceutical companies.

\section{Subcutaneous delivery}

To date, over 100 different applications of subcutaneous injectable biologics have been approved for clinical use. The bioavailability of $\mathrm{mAbs}$ that are subcutaneously injected in the clinic range from $50-85 \%$ (published in product inserts of mAbs). Although this delivery method is still invasive, subcutaneous injections are more convenient (for example, allow selfadministration) than intravenous administration ${ }^{6}$, and this advantage is one of the main driving factors in their increased use and continued development as alternatives to intravenous injections. The main limitations of intravenous injections, which are addressed by subcutaneous injection, are the need for a trained professional to perform the procedure and the need for long infusions. Subcutaneous injections can be self-administered, which improves patient acceptance and compliance, and the use of existing depot-based formulations for peptides can decrease dosing frequency ${ }^{7}$. Efforts into developing subcutaneous alternatives for biologics delivery are highlighted here to illustrate their potential and the immense interest in developing less-invasive approaches to biologics delivery.
Fundamental barriers. Most biologics that are subcutaneously injected will be systemically absorbed by capillaries after penetrating through the extracellular matrix or transported through the lymphatic system (FIG. 1a). Absorption kinetics are regulated by the diffusion of the biologic from the injection site to the absorption site and the convective fluid flow, which are both limited by the extracellular matrix, which consists predominately of structural proteins ${ }^{8}$. These physical absorption barriers are not the primary challenge for the majority of subcutaneously administered biologics; instead, the main limitation is a disconnect between the maximum injectable volume and the amount of biologic needed to achieve therapeutic efficacy. For example, the limited injectable volume of subcutaneous injections $(<1.5-2 \mathrm{~mL})$ and the high doses that need to be administered in order to achieve therapeutically meaningful systemic concentrations of mAbs create formulation challenges. This is further exacerbated by the low and variable bioavailability of $\mathrm{mAbs}$ from the subcutaneous space $^{9}$, which is affected by the injection site ${ }^{10}$, dose ${ }^{11}$ and diffusional limitations ${ }^{12}$. The lower bioavailability compared with that of intravenous injections can also originate from interactions between the antibody and the local subcutaneous tissue, resulting in aggregation of the injected biologic with extracellular matrix components ${ }^{13}$, immune cell interactions ${ }^{14}$ and foreign-body 


\section{Box 1 | The dose and size of biologics dictate delivery strategy}

Development of alternative strategies for the non-invasive delivery of biologics must consider the molecular mass of the biologic, the therapeutic dose and the relationship between these two parameters. Biologic size and dose can limit absorption, especially for biologics that require large doses (such as monoclonal antibody (mAb)-based antagonists). High therapeutic doses, often as high as mg per kg, necessitate highly concentrated solutions and sufficient surface area for absorption. Drug concentration requirements are often limiting for large biomolecules such as mAbs, and surface area requirements may preclude novel delivery approaches to low-surface-area absorptive sites (such as the buccal and nasal surfaces) in favour of absorptive sites with a large interface (namely, the lungs and intestines). Additionally, a high dose of the same biologic will have a different rate of diffusion than a low dose because the concentration gradient is the diffusional driving force.

Likewise, biologic properties such as molecular mass dictate the rate of diffusion, absorption and final systemic concentration. Furthermore, each delivery site features unique physiological characteristics and barrier properties and thus diffusional limitations are specific to each absorptive tissue site; as such, the delivery route must take into account the molecular mass of the biologic. For example, absorption via the intestines (following oral delivery) requires diffusion of the drug through the mucus before transport across epithelial cells. In the lungs, diffusion across lung surfactant and mucus must occur before epithelial transport. In addition to molecular mass, physical properties of the biologic (such as hydrophobicity and charge) must be considered, as they can influence diffusion or absorption. Biologic properties must be acknowledged to inform delivery site and approach.

To take biologic properties and the required therapeutic dose into account, the role and function of biological barriers must be understood when considering alternative delivery routes. These considerations are especially important for alternative and non-invasive routes of delivery because diffusion, absorption and dosing do not need to be considered in the same context for intravenous delivery, which, by definition, achieves $100 \%$ bioavailability. with host-sourced hyaluronidases limited their repeated $u^{23,24}$. Recombinant hyaluronidases based on soluble recombinant human hyaluronidase $\mathrm{PH} 20$ were eventually introduced and addressed these issues ${ }^{20}$. Hylenex, a recombinant hyaluronidase for human injection, was approved by the FDA in 2005 for use as a dispersant to increase the absorption of drugs ${ }^{25}$. Since then, hyaluronidases have been approved by the FDA for subcutaneous delivery with rituximab (for lymphoma) ${ }^{26}$ and immune globulin (for primary immunodeficiency) ${ }^{27}$ and by the European Medicines Agency (EMA) for the delivery of trastuzumab (for breast cancer) ${ }^{28}$ (TABLE 2). Many current trials to improve subcutaneous delivery are ongoing or recently completed for peptides such as insulin (NCT01275131), daratumumab (NCT03301220) and pertuzumab (NCT02738970). Overall, the delivery of higher dosing volumes $(>2 \mathrm{~mL}$ ) enabled by the hyaluronidase-based technologies alleviates the need to develop high-concentration formulations for antibodies, which can be difficult to achieve owing to viscosity, aggregation and phase separation challenges ${ }^{29}$.

Formulation approaches have also contributed to reshaping how peptides can be delivered subcutaneously $^{30}$ (FIG. 1b). Lupron Depot (which contains leuprolide) is one of the original examples of a microparticle formulation that decreased the number and frequency of injections required to achieve an equivalent therapeutic dose $\mathrm{e}^{31,32}$. By virtue of encapsulation into a polymer, interactions between the delivered biologics, the extracellular matrix and the absorption sites can be better controlled. Although not explicitly studied, it is possible that polymer-based peptide depots provide a means to mediate absorption by altering the biologic concentration at the absorption site through controlled release or to mitigate interactions between the biologic and proteins in the extracellular matrix. This is clearly a delicate balance, yet many biologic-based polymer depot products, such as those for the delivery of somatotropin (Nutropin Depot) $)^{33}$, leuprolide (Eligard) ${ }^{34}$, risperidone (Risperdal Consta $)^{35}$, naltrexone (Vivitrol) ${ }^{36}$ and exenatide (Bydureon) $)^{37}$, have found clinical and commercial success with these formulation approaches ${ }^{7}$. In general, these examples highlight how a formulation approach can be used to control the biologic-extracellular matrix environment to limit dosing frequency and improve compliance.

Recent preclinical strategies. Efforts are being made to better understand subcutaneous tissue barriers and thus develop better approaches to overcome these challenges. One approach involves leveraging simulations to evaluate and predict biologic bioavailability ${ }^{38,39}$. Predicting absorption of biologics following subcutaneous injection is an active area of preclinical research, and estimating pharmacokinetic and pharmacodynamic parameters (such as clearance, bioavailability and distribution volumes) from preclinical models would accelerate development and optimization of subcutaneous biologic administration. Early-stage experimental approaches to create subcutaneous depots of living cells that enable constant production, secretion and delivery of biologics are being developed ${ }^{40,41}$ (FIG. 1 b). Biologic-producing cells related to immunogenicity reactions and impurities better control over bioavailability. In the earliest wor using naturally derived hyaluronidase $\mathrm{e}^{21}$, hyaluronidase enhanced the dispersion and absorption of dyes and
antiviral vaccines ${ }^{21,22}$. However, substantial challenges injectable volume - can make this delivery route more

responses to polymer-formulated biologics (for example,
peptide depots based on poly(lactic-co-glycolic acid) $)^{15-17}$. Successful approaches to address these fundamental barpatient compliance and improved therapeutic efficacy of ronidases, the co-injected biologic exhibits improved dispersion and tissue permeability ${ }^{19}$ (FIG. 1b). This increase the delivered biologic to interact with a greater absorptive surface area ${ }^{20}$. Increased biologic dispersion simulcan be used with typical subcutaneous delivery. These two advantages - increased absorption and increased injectable volume - can make this delivery route more 


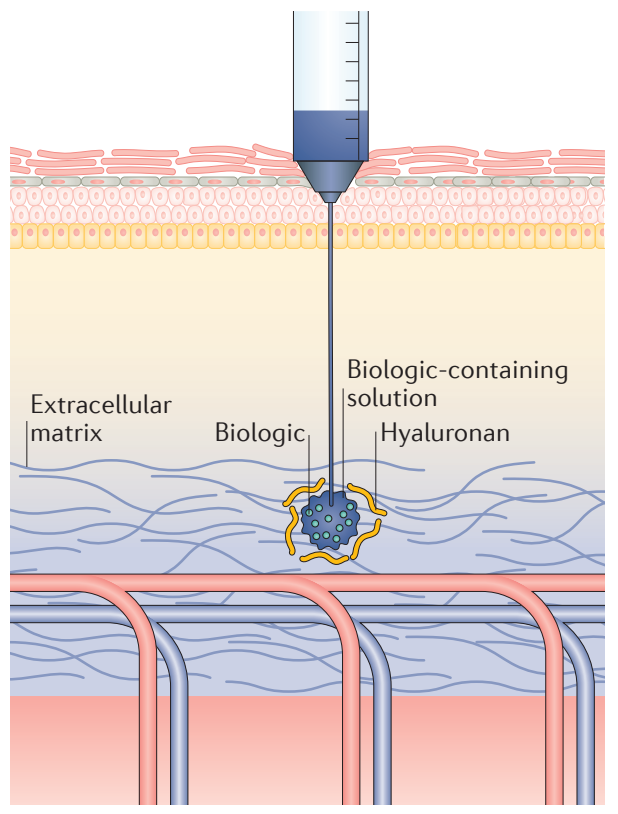

b New approaches

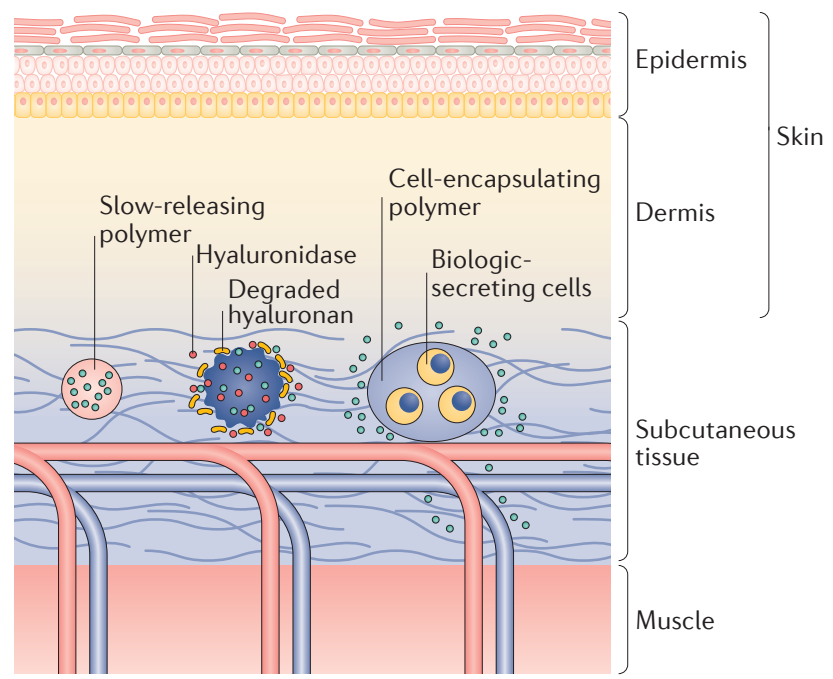

Figure 1 | Subcutaneous barriers, products and new approaches. a | Delivery barriers that limit biologic absorption via the subcutaneous route include extracellular matrix proteins such as hyaluronan. $\mathbf{b} \mid$ Approaches to overcome diffusion and dispersion limitations. Leuprolide acetate for depot suspension (Lupron Depot) overcomes the issue of repeated doses for peptide delivery through controlled release. Hyaluronidase, which degrades hyaluronan, can enable delivery by increasing the tissue surface area to which the biologic formulation has access. A preclinical 'cell factory' approach has also been developed for limiting the repeated administration of biologics. In this example, pancreatic islet cells are encapsulated in a polymer to enable long-term encapsulation of biologic-secreting cells.

can potentially mitigate the need for repeated doses of peptides, antibodies or antigens in favour of a single subcutaneous injection. Building on the foundation of microparticle technologies such as Lupron Depot, these approaches typically rely on microencapsulation to prevent the overgrowth - and potential clearance - of the living drug factory ${ }^{42}$. Efforts to understand how material properties affect the rejection of subcutaneous cell-based implants is a highly active area of research ${ }^{42,43}$. One of the most investigated applications of this approach is the implantation of pancreatic islet cells to reverse diabetes ${ }^{40,44-46}$. Numerous approaches and novel aspects have been tested for islet transplantation, including injectable and implantable formulations, the use of primary-cell islets or stem-cell-derived $\beta$-cells, and approaches to control the immune response ${ }^{47-49}$. A potential single subcutaneous injection for glucose-responsive insulin delivery and diabetes reversal would dramatically change diabetes treatment. These drug factory approaches have also been investigated preclinically for the delivery of vaccines ${ }^{50}$, antibodies $^{51}$ and other biologics ${ }^{52}$.

Snapshot of current clinical trials. Hundreds of clinical trials for the subcutaneous administration of antibodies, vaccines, proteins and peptides are currently ongoing (not completed) (Supplementary Table 1). Of these trials, recombinant hyaluronidases are one of the most active technologies for enhancing subcutaneous delivery. Recent efforts into recombinant hyaluronidases are focused on broadening the indications beyond the currently approved uses. Over ten current (not completed) clinical trials are investigating recombinant hyaluronidases to improve the subcutaneous delivery of proteins, such as immunoglobulins, for the treatment of diseases including multifocal motor neuropathy, myeloma and breast cancer.

Critical analysis and future challenges. Approaches to improve the subcutaneous delivery of biologics have been established; polymeric microparticle depots and hyaluronidases are the best clinical examples. The advantages that these systems offer include controlled release, physically separating the biologic from the subcutaneous microenvironment (for polymeric microparticles) and improved dispersion (for hyaluronidases). Other modes of drug delivery, such as intravenous injections, have seen advances such as stimuli-responsive systems $^{53,54}$ (for example, glucose-responsive or $\mathrm{pH}$ responsive), approaches to modify biologic half-life ${ }^{55,56}$ (such as PEGylation) and targeted delivery ${ }^{57,58}$ (such as antibody-drug conjugates). It is therefore perhaps surprising that depots, which were among the original biomaterial-based delivery systems, have yet to include these recent game-changing advances. A critical look suggests that because these modifications typically involve an increase in the size of the biologic, which negatively affects biologic diffusion and absorption, they have not been amenable to the subcutaneous delivery route, which faces significant diffusion and absorption hurdles. As such, perhaps the true bottleneck in 
Table 2 | FDA-approved or EMA-approved biologics for subcutaneous delivery with hyaluronidases

\begin{tabular}{|c|c|c|c|c|}
\hline $\begin{array}{l}\text { Name } \\
\text { (company) }\end{array}$ & $\begin{array}{l}\text { Route, biologic and } \\
\text { formulation }\end{array}$ & Approved indications & Investigated indications & $\begin{array}{l}\text { Number of trials on } \\
\text { ClinicalTrials.gov }\end{array}$ \\
\hline $\begin{array}{l}\text { HyQvia } \\
\text { (Baxalta) }\end{array}$ & $\begin{array}{l}\text { Subcutaneous } \\
\text { immunoglobulin (10\%) } \\
\text { with recombinant human } \\
\text { hyaluronidase (rHuPH20) }\end{array}$ & $\begin{array}{l}\text { Primary immunodeficiency } \\
\text { in adults }\end{array}$ & $\begin{array}{l}\text { - Multifocal motor neuropathy } \\
\text { - Chronic inflammatory demyelinating } \\
\text { polyradiculoneuropathy } \\
\text { - Primary immunodeficiency in adults } \\
\text { - Secondary immunodeficiency in adults }\end{array}$ & $>10$ \\
\hline $\begin{array}{l}\text { Rituxan Hycela } \\
\text { (Genentech/ } \\
\text { Roche) }\end{array}$ & $\begin{array}{l}\text { Subcutaneous rituximab } \\
\text { with human hyaluronidase }\end{array}$ & $\begin{array}{l}\text { - Follicular lymphoma } \\
\text { - Diffuse large B cell lymphoma } \\
\text { - Chronic lymphocytic leukaemia }\end{array}$ & Chronic lymphocytic leukaemia & 1 \\
\hline $\begin{array}{l}\text { Herceptin SC } \\
\text { (Genentech/ } \\
\text { Roche) }\end{array}$ & $\begin{array}{l}\text { Subcutaneous trastuzumab } \\
\text { with recombinant human } \\
\text { hyaluronidase (rHuPH20) }\end{array}$ & Breast cancer & Breast cancer & $>20$ \\
\hline
\end{tabular}

EMA, European Medicines Agency; FDA, US Food and Drug Administration. Accessed from https://clinicaltrials.gov/ct2/home on 18 June 2018.

subcutaneous delivery is in developing novel methods to enable the absorption of larger, more functional and more efficacious next-generation biologics.

\section{Transdermal delivery}

Transdermal delivery, a non-parenteral delivery route, offers several advantages including sustained release, painless administration, ease of termination and avoidance of first-pass metabolism. Transdermal approaches can also offer particular advantages for dermatological diseases in the form of local treatment.

Fundamental barriers. Substantial barriers limit the transdermal delivery of biologics (FIG. 2a). Mammalian skin has evolved to enhance its main function, which is to act as a protective barrier to the external world ${ }^{59}$. As such, the main factors that limit the systemic delivery of biologics via transdermal delivery are the natural barrier functions of our skin ${ }^{60}$. The topmost layer of the skin is the stratum corneum and is the first and most difficult barrier to transdermal drug delivery ${ }^{61,62}$. The stratum corneum is located in the epidermis and is approximately $10-20 \mu \mathrm{m}$ thick $^{61,62}$. The major cellular component of the stratum corneum is non-living cells called corneocytes, which are mechanically robust cells that confer the skin's barrier properties against physical and chemical intrusions. For the most part, corneocytes are non-living and, therefore, active cellular transport processes are less amenable to manipulation ${ }^{63}$. Importantly, corneocytes are constantly replaced ${ }^{64}$, thus providing a direct mechanism for constant barrier replenishment and an active mechanism to push unabsorbed drugs outwards from the body. The stratum corneum also contains multiple lipid bilayers that surround corneocytes ${ }^{65}$, and biologics must pass through these lipid bilayers because passage through corneocytes is not typically possible ${ }^{61,62}$. The distinct hydrophilic and hydrophobic sections within the tortuous lipid bilayers that span the whole depth of the stratum corneum severely limit biologic transport. Once the biologic of interest passes through the stratum corneum, it must then navigate through the viable epidermis, which lacks blood vessels and limits diffusion or permeation, to the dermis ${ }^{66}$, where systemic absorption occurs. Given the large size of biologics, these barriers are particularly challenging.
Seminal advances to overcome barriers in the clinic. A number of approaches have been developed to overcome the skin barrier. Typically, these methods fall into two categories: methods that rely on drug diffusion through the intact skin barrier ${ }^{67}$ and methods that physically disrupt and bypass the barrier ${ }^{68}$. In the latter case, chemical permeation enhancers have shown success for the delivery of small molecules ${ }^{69,70}$; however, their use for enhancing transdermal biologic delivery has been mini$\mathrm{mal}^{71,72}$, especially when used alone. For increasing diffusion through intact skin, transdermal patches have been used clinically for nearly four decades for the transdermal delivery of hormones, opioids, small-molecule anaesthetics and many other drugs ${ }^{7,61,62}$. Traditional transdermal patches are not widely used for biologic delivery owing to the size of the molecules; transdermal-patch-mediated delivery of hormones is the exception. Still, early successes in small-molecule drug delivery via patches have shaped the transdermal delivery field. Patches are an ideal drug delivery system because they can improve the ease of administration, patient convenience, non-invasiveness and patient compliance. In efforts to achieve the same success for biologics, the use of devices to modulate the skin barrier via ultrasound ${ }^{73,74}$, iontophoresis ${ }^{75}$, electroporation $^{76}$, microneedles ${ }^{77-79}$ and jet injections ${ }^{80}$ has led to clinical successes ${ }^{62}$ (FIG. 2b). Unlike traditional transdermal patches, these device-based approaches can disrupt the skin barrier such that biologics can be delivered transdermally. Past clinical trials have investigated the delivery of biologics, including fertility hormones and insulin, using iontophoresis. Few clinical studies have been initiated for the delivery of biologics using ultrasound and traditional jet injectors (newer versions of jet injectors have a microneedle component).

Microneedles are the most widely used technology for the transdermal delivery of biologics in current and past clinical trials ${ }^{81}$. Microneedles function similarly to conventional needles that must pierce the skin to achieve systemic delivery ${ }^{77-79}$. Microneedles can range in size up to a few hundred micrometres and are designed to be sharp enough to pierce and bypass the stratum corneum to enable systemic drug absorption (FIG. 2). Microneedles offer many of the same advantages as the standard transdermal patch; they cause minimal pain and discomfort ${ }^{82}$, can be applied by the patients themselves and thereby 


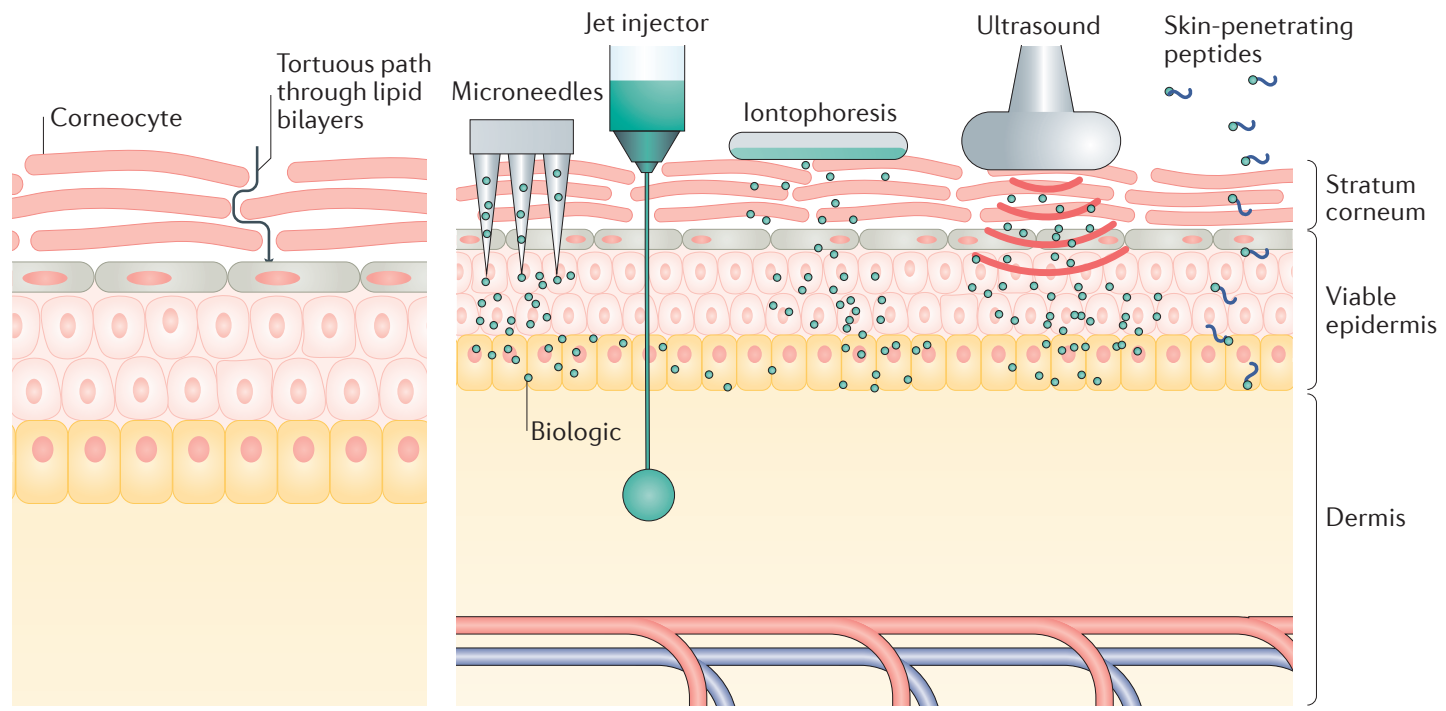

Figure 2 | Transdermal barriers, products and new approaches. a | Delivery barriers such as the stratum corneum and tortuous path through lipid bilayers limit biologic absorption via the transdermal route. $\mathbf{b} \mid$ Approaches to overcome these barriers to achieve transdermal biologic delivery include microneedles, jet injectors, iontophoresis devices and ultrasound devices, which physically disrupt the stratum corneum to improve diffusion and transport of biologics across the lipid bilayers and through the spaces between the corneocytes. Skin-penetrating peptides bind to the biologic and key proteins in the skin (such as keratin) to enable active transport.

substantially enhance patient compliance and convenience. Microneedles can be manufactured to align as an array on conventional transdermal patches and provide a direct means to control dosing via the number and loading of microneedles. Polymer chemistry and formulation approaches can also be leveraged to design microneedles for controlled and predictable biologic delivery ${ }^{83}$. Specific modifications to the microneedles themselves can endow them with specific characteristics; for example, polymer choice can be used to control biologic release and stability ${ }^{83}$, microneedle size and shape can be used control penetration depth ${ }^{77}$, permeation enhancers can be included to improve absorption, multiple drugs or biologics can be combined for synergistic delivery, or the microneedle structure (for example, hollow or solid) can be modified to control drug loading and release. Because of their ease of use and capacity for customization, microneedles have been successfully utilized in clinical settings. The first clinical examples of this include the use of microneedles to deliver influenza vaccines, insulin or parathyroid hormone (for osteoporosis treatment).

Recent preclinical strategies. A number of preclinical strategies for the transdermal delivery of biologics have not yet entered the clinic. A recent example is the use of transport-promoting peptides (FIG. 2b). A number of novel peptides have been described that can improve the transdermal delivery of biologics through a variety of mechanisms. Peptides that have shown preclinical success for the delivery of biologics (including small interfering RNA (siRNA), glyceraldehyde-3-phosphate dehydrogenase (GAPDH), interleukin-10 and insulin) include pore-forming peptides such as magainin ${ }^{84,85}$, cell-penetrating peptides ${ }^{86}$, peptides that create transient openings in the skin ${ }^{87}$, skin-penetrating peptides ${ }^{88}$ and peptides with protein transduction domains ${ }^{89}$. Peptidemediated transdermal approaches have several unique advantages over other barrier-breaching technologies. For example, some transport-promoting peptides are amenable to coadministration or pre-administration, which avoids modification to the delivered biologic through covalent or other means. Preliminary work has shown that peptides that enhance transdermal delivery by modulating the skin barrier can also be used synergistically with other transdermal technologies such as liposomes ${ }^{90}$; these efforts may be extended to devicebased approaches (such as ultrasound or iontophoresis), chemical permeation enhancers or combinations of these (including liposomes, organic solvents and skinpenetrating peptides). For example, a liposome formulated with both permeation-enhancing ethanol and a skin-penetrating peptide was shown to increase skin accumulation of the siRNA by over sixfold compared with controls ${ }^{91}$. Novel peptides can be identified and discovered using high-throughput screening approaches such as phage display ${ }^{87,88}$. Peptide docking and other computational approaches can be used to evaluate the contribution of individual amino acids in peptide sequences to optimize transport ${ }^{92}$ and even to facilitate the design of peptides that contain non-natural amino acids, which can enhance their stability. Combinations of peptides that operate through distinct mechanisms (for example, pore formation or cell penetration) may also synergistically improve biologic delivery. Transportpromoting peptides can be chemically synthesized, which avoids the need for biological production, a method that can increase costs, regulation and inconsistency of the product, depending on the cell source.
Liposomes

nanoparticles with tuneable physicochemical parameters that are designed to encapsulate and deliver biologics. 
Next-generation microneedle systems that build on existing clinical successes are being developed but have yet to enter clinical application. These microneedles endow biologically responsive and stimuli-responsive functionalities that are triggered by specific microenvironmental features. In one example, microneedles have been designed to harbour and deliver insulin from glucose-responsive nanoparticles. These nanoparticles are made of hypoxia-responsive polymers that are reduced in hypoxic microenvironments, such as occurs from the oxidation of blood glucose; the particles then subcutaneously degrade and release insulin. As such, this system specifically responds to elevated blood glucose levels and can be used to regulate insulin delivery and concentration in real time ${ }^{93}$, potentially with a single administration. A follow-up study reported a microneedle that incorporated living pancreatic $\beta$-cells to provide a constant source of insulin, thus limiting the need for repeated administration ${ }^{94}$. Other stimuliresponsive microneedle systems have been used with near-infrared light irradiation to improve, for example, the transdermal delivery of B16F10, a whole tumour antigen vaccine against melanoma, which should locally and systemically stimulate the immune response. The microneedles, designed for prolonged release, were loaded with B16F10 antigen and melanin. Following absorption of external near-infrared light, melanin transforms this energy into heat, which enhanced uptake of the released B16F10 antigen by dendritic cells compared with near-infrared-light-free controls. Furthermore, local $\mathrm{T}$ cell infiltration and cytokine release, as well as an increased systemic immune response to the B16F10 antigen, were observed following near-infrared light exposure ${ }^{95}$. These advanced microneedle systems can breach biological barriers (as can the early microneedle systems) and provide additional unique functions that do not currently exist in clinical care. For example, these systems can be developed for one-time application by facilitating release and deposition of the stimuli-responsive components in the skin, which will be therapeutically active only after disease-associated microenvironmental cues are present. This could enable the non-invasive and long-lasting delivery of prophylactic biologics. The highlighted example using living pancreatic $\beta$-cells effectively demonstrates how a microneedle system can be used as a semi-permanent port to enable the real-time and responsive delivery of biologics.

Ionic liquids have recently emerged as a topical technology ${ }^{96}$ for the transdermal delivery of biologics. The physicochemical properties of ionic liquids can be controlled and therefore designed to improve the transport and solubility of biologics ${ }^{97}$. For example, ionic liquids have been shown to enhance cell membrane permeability via improved transport into the stratum corneum and improved navigation through lipid channels ${ }^{98}$. These liquids have also been shown to fluidize cell membranes to improve diffusion ${ }^{99}$ and extract or displace transport-limiting lipids found in the stratum corneum ${ }^{100}$. By virtue of having tuneable physicochemical properties, ionic liquids can be specifically designed to achieve the desired solubility, concentration and viscosity, which all directly control transdermal diffusion and delivery. Recent studies have utilized ionic liquids for the systemic delivery of large proteins $(>60 \mathrm{kDa})$ such as bovine serum albumin and ovalbumin, as well as peptides such as insulin ${ }^{100}$. Most recently, choline-based and geranate-based ionic liquids were shown to be capable of extracting lipids in the stratum corneum and provided a therapeutic dose of insulin that reduced blood glucose by $40 \%$ in 4 hours, sustained over 12 hours, in rats ${ }^{100}$. Transdermal delivery of biologics via ionic liquids can occur without physical disruption devices or chemical permeation or penetration enhancers; as such, combination approaches may prove even more successful. Although ionic liquids are still in the preclinical stage, efforts to elucidate the mechanisms of transdermal transport, evaluate host toxicity, describe interactions with topical microorganisms and extend the application to therapeutic use are well underway ${ }^{97}$.

Snapshot of current clinical trials. Many (>20) biologics are being investigated for delivery via the transdermal route (TABLE 3). More than ten of these have advanced to phase II or III clinical studies. The majority of the current clinical trials $(>15)$ are based on microneedle or jet injection systems, which indicates that the leading strategy to enable transdermal delivery of biologics relies on physical disruption. These trials are evaluating the delivery of numerous distinct biologics, ranging from large antigen vaccines to small peptides such as insulin. A few of the remaining current clinical trials utilize passive transdermal patches for the delivery of smaller peptides (such as teriparatide for osteoporosis, gonadotropin for infertility or glucagon for hypoglycaemia). Our search found no currently active trials for the transdermal delivery of proteins or antibodies other than vaccines. However, a phase II trial based on a hydrogel formulation for delivery of an antitumour necrosis factor antibody was recently completed (NCT01936337). Of the microneedle peptide trials, only the studies of teriparatide and abaloparatide have advanced to phase II trials. Jet injectors that are combined with microneedles are being studied for the delivery of insulin, proinsulin and islet cell autoantigenic peptides for the treatment of diabetes. Patches that leverage iontophoresis-mediated barrier disruption are in trials for the delivery of gonadotropin hormone or insulin for the treatment of infertility or spinal cord injury, respectively. Microneedle approaches are also being investigated for vaccine delivery, and include delivery of approved subunit vaccines (such as Fluvirin), inactivated vaccines (for polio or rabies), vector or plasmid vaccines (such as those designed to treat peanut allergies or cancer) and live vaccines (against hepatitis or varicella). Many of these have advanced to phase II trials, and one (recombinant hepatitis $B$ vaccine) has advanced to phase III. Of particular note, Fluzone Intradermal from Sanofi is clinically approved, and there are currently over 50 clinical trials utilizing their microinjection system for intradermal injection of the live flu vaccine. 
Critical analysis and future challenges. A critical look at the clinical landscape highlights the interest and potential for transdermal delivery systems in developing non-invasive routes for biologic delivery. Unlike transdermal patches for small-molecule delivery, which are also being used for a few peptides, the majority of transdermal approaches to deliver biologics rely on external devices to physically disrupt the stratum corneum. The size of the biologic dictates the approach for transdermal delivery; currently, successful systemic delivery of large biologics requires physical disruption of the skin barrier. This sets transdermal delivery apart from other delivery routes because the current clinical landscape is shifted towards devices (such as ultrasound and iontophoresis) or physical disruption approaches (such as microneedles) as opposed to novel formulation-based methods (such as ionic liquids and chemical permeation enhancers). Perhaps the opportunity for true disruption is in discovering or developing formulation-based approaches that enable transdermal delivery of large biologics. A first attempt at this may involve combining established physical disruption approaches with formulation approaches and directly comparing the combination with the individual constituents. This may provide initial insights as to which formulation approaches are most compatible with larger biologics and therefore most promising for further development. No antibodies are currently being delivered via the transdermal route in the clinic. Because the majority of recent approvals and interest in biologics are in antibodies, transdermal approaches need to be developed for antibody delivery. It is likely that this will be preceded by the successful transdermal delivery of smaller peptides. A future challenge that may prevent the widespread use of transdermal delivery of antibodies is the cost, which could be prohibitively high owing to the low bioavailability of transdermally delivered antibodies, the time and costs associated with mAb production, and the large size of the dose that will likely be required. This cost-benefit analysis may appear unfavourable compared with intravenous injections, which, although invasive, require a much smaller dose owing to the high bioavailability of biologics delivered intravenously.

\section{Oral delivery}

Oral delivery is the most widely used route of administration for small-molecule drugs owing to its noninvasive nature, which is convenient for patients and thus has high patient compliance, and to its limited dosing frequency, which has been enabled by controlled-release

Table 3 | Current trials and approved products for the transdermal delivery of biologics

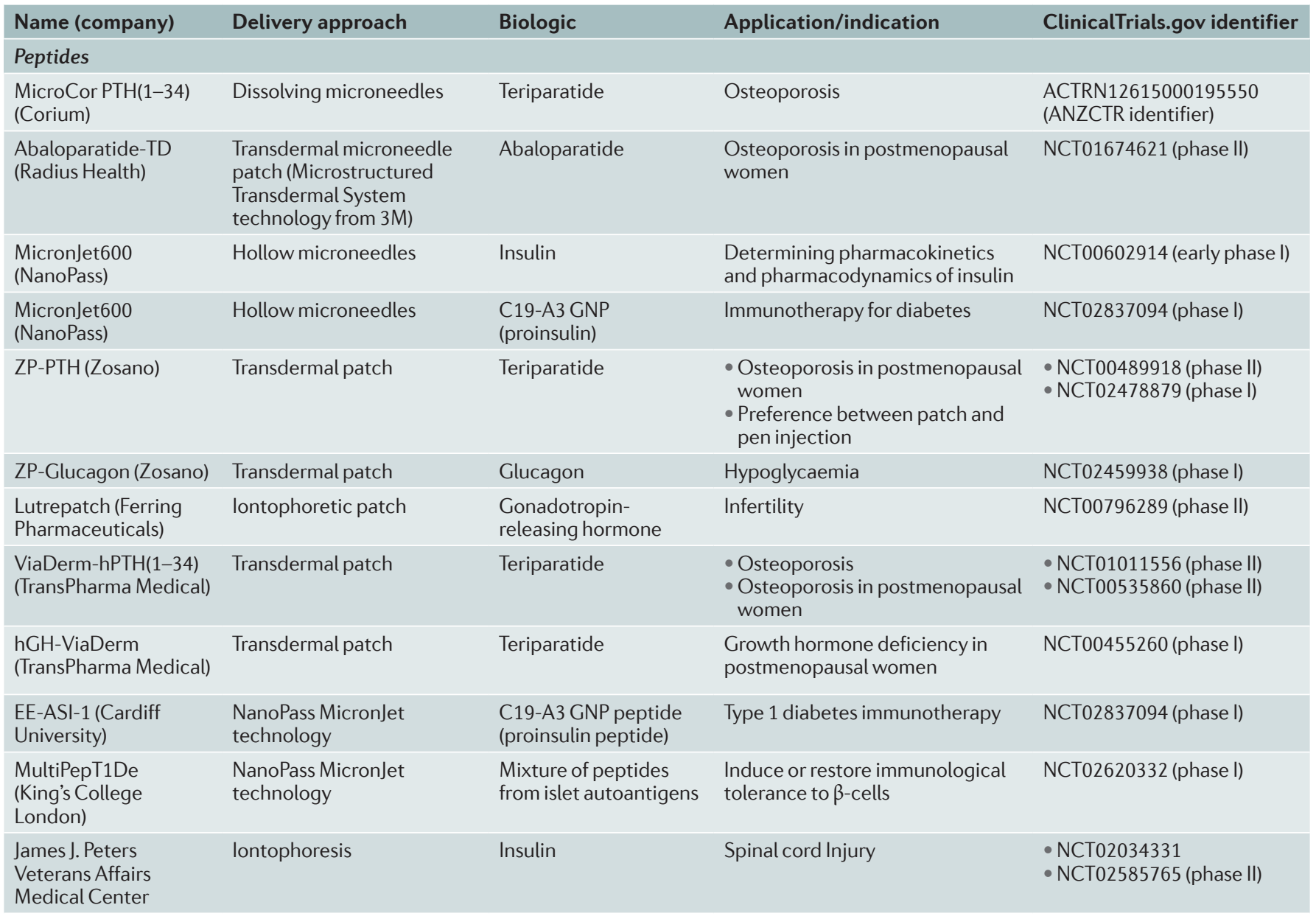


formulations. These advantages are present in standard oral delivery technologies such as solid dosage forms (capsules and tablets), syrups and other oral dosage forms. Technologies that enable and facilitate the oral delivery of biologics are highly desirable but remain elusive.

Fundamental barriers. Although oral delivery remains the mainstay for the administration of small molecules, it cannot be reliably used to deliver proteins and peptides owing to poor transport across the intestinal membrane and poor absorption into systemic circulation ${ }^{101}$ (FIG. 3a). At the lumen-intestinal interface, intestinal epithelial cells act as a physical barrier to limit the transport of biologics across the intestines. Transport therefore occurs either through passive diffusion (via the paracellular ${ }^{102}$ or transcellular ${ }^{103}$ routes) or by active transport across the intestinal epithelium (through carrier-mediated transport mechanisms ${ }^{104}$ or receptor-mediated transcytosis ${ }^{105}$ ).
Following transport across the intestinal barrier, the drug can be directly absorbed into systemic circulation via capillaries that interact with the basement membrane of the epithelial cells. Another physical barrier to intestinal absorption is the intestinal mucus that resides above the intestinal epithelium ${ }^{106}$. Mucus is largely composed of densely glycosylated proteins that are constantly being shed and cleared through the gastrointestinal tract ${ }^{107}$. Mucus may also pose a major steric barrier to biologic delivery, as it can limit diffusion or potentially trap biologics before they have the opportunity to interact with the intestinal epithelium ${ }^{108}$. Recent work has shown that the mucosal barrier can also trap pathogens ${ }^{109}$; similar interactions may prevent diffusion or transport of biologics. The gastrointestinal tract is a dynamic site, and because of this, the transit time of swallowed medications must be sufficiently slow to allow interactions with and subsequent diffusion through the mucus ${ }^{110}$. In addition to the physical limitations that lead to poor

Table 3 cont. | Current trials and approved products for the transdermal delivery of biologics

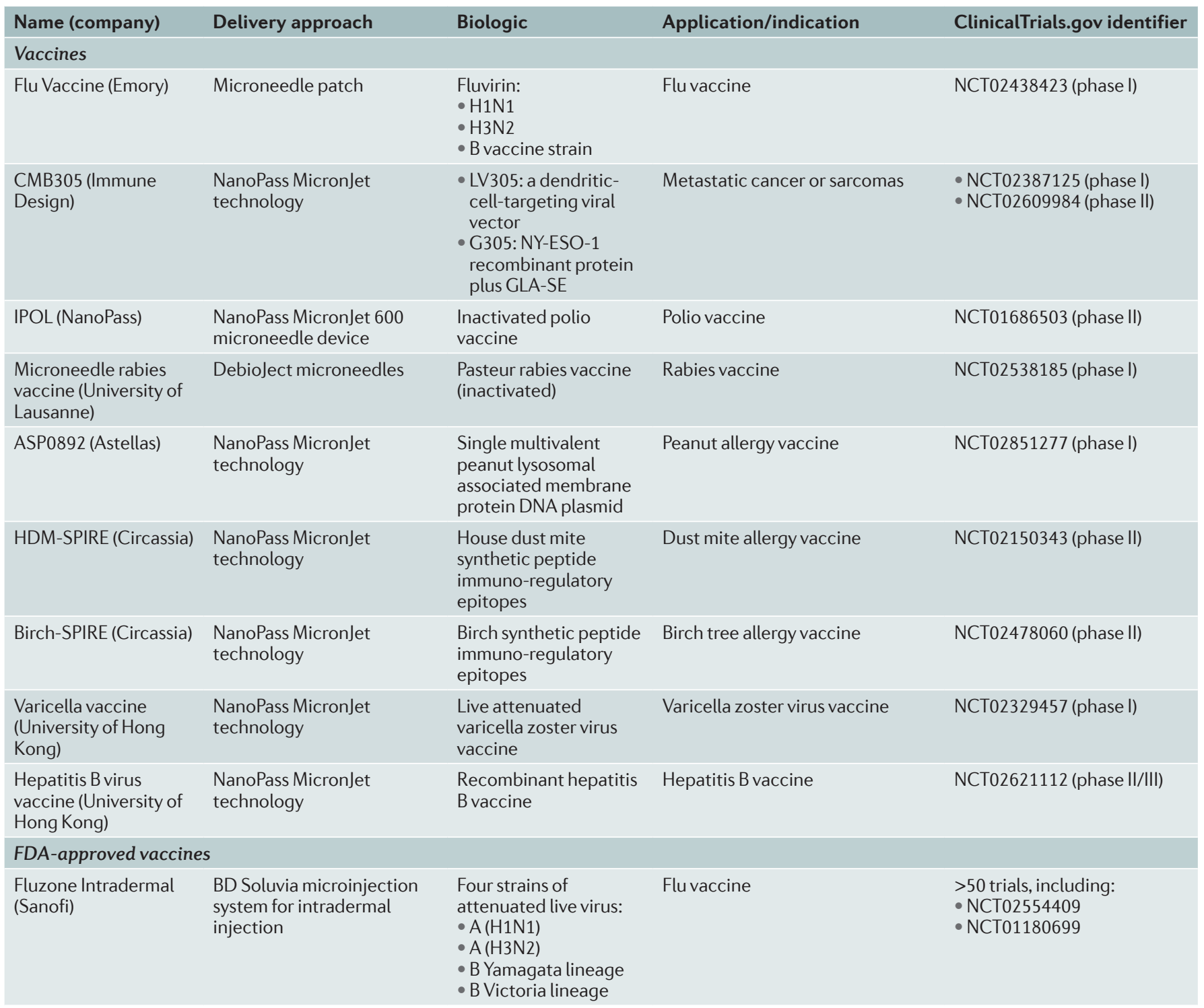


a Delivery challenges

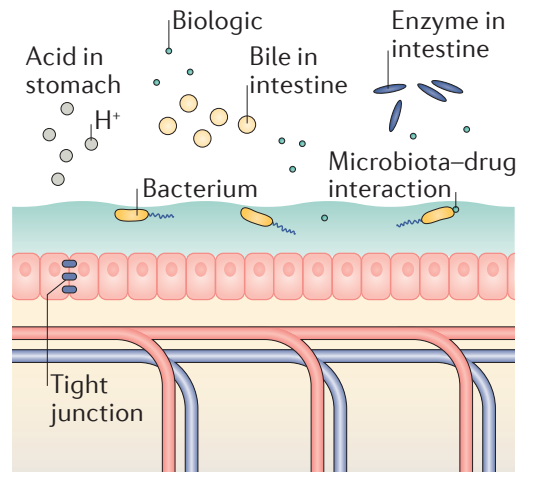

b New approaches

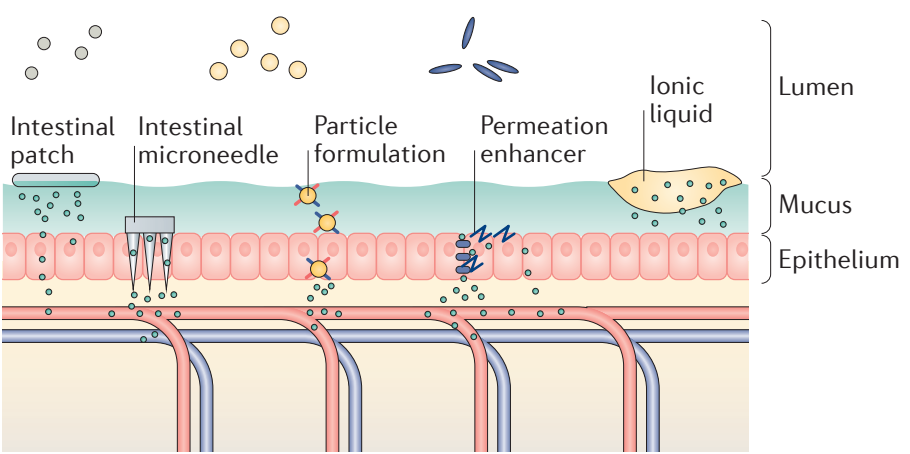

Figure 3 | Oral barriers, products and new approaches. a | Delivery barriers and microenvironmental challenges that limit biologic absorption via the oral route. $\mathbf{b} \mid$ Approaches to overcome these barriers and microenvironmental challenges. Intestinal patches improve absorption by enhancing mucoadhesion and subsequently diffusion. Intestinal microneedles can be used to facilitate absorption by physically breaching the epithelium. Particle formulations can improve transport by including intestine-targeting ligands, mucoadhesive coatings or mucopenetrative coatings. Permeation enhancers can be used to disrupt tight junctions or cell membranes to facilitate enhanced transport across the epithelium. lonic liquids can be used to promote interactions with the mucous layer and provide permeation enhancement to facilitate improved epithelial transport.

absorption, chemical entities in our gastrointestinal tract, including bile salts, gastric acids ${ }^{111}$ or proteases ${ }^{112}$, can either render biologics therapeutically inactive or induce irreversible changes that limit their absorption. Another consideration is the microbiome, as it has been reported that microorganisms in our gastrointestinal tract can affect the efficacy ${ }^{113}$, and likely the absorption, of drugs. First-pass metabolism will also limit the efficacy of orally administered biologics ${ }^{114}$. Altogether, the combination of physical and chemical factors that limit systemic absorption will occur both in series and in parallel and presents a formidable set of complex challenges to the delivery of orally administered biologics. Efforts to address these challenges for systemic biologic delivery are highlighted below.

Seminal advances to overcome barriers in the clinic. The most widely used approach to overcome many of these oral delivery barriers is the use of capsules or tablets (FIG. 3b). Currently, capsules and/or tablets are the gold-standard dosage form for oral delivery (and therefore arguably for drug delivery in general), as they offer unparalleled patient acceptance. Capsules and/or tablets offer many advantages for drug delivery, such as solid (tablets) or liquid (capsules) dosage form delivery; control over dissolution (which can be timed release via polymer coatings) ${ }^{115}$, residence time (using floating systems) ${ }^{116}$ and release (which can be osmotically controlled) ${ }^{117}$; protection from chemical challenges (including acids, enzymes and bile); straightforward inclusion of stabilizing or absorption-enhancing excipients; and superb patient convenience and compliance (due to self-administration, pre-measured doses, colour coding for identification and other features). These features and advantages can be found in many commercially available pharmaceutical products, and each can be described as an individual seminal advance to capsules.
Building on these longstanding advances by addressing specific delivery barriers for biologics is an active area of preclinical and early-stage clinical research. One of the earliest findings was that insulin absorption via the oral route could be enhanced by coadministering it alongside alcohol ${ }^{118}$, an advance that spurred interest in absorption and permeation enhancers and their inclusion in traditional oral delivery dosage forms. As with transdermal delivery approaches, permeation enhancers are widely researched for increasing the bioavailability of orally delivered biologics (FIG. 3). Permeation enhancers ${ }^{119}$ for oral biologic delivery include chelating agents ${ }^{118}$, lipids ${ }^{120}$, organic solvents ${ }^{121}$, biomolecules (such as bile acids and toxins) ${ }^{122}$ and polymers ${ }^{123}$. Solubility enhancers, which are distinct from permeation enhancers, have been used for the oral delivery of cyclosporin A. Cyclosporin A is an immunosuppressive peptide that is clinically approved for preventing organ transplant rejection and delivered orally in formulations that use surfactants to improve solubility and thus bioavailability ${ }^{124,125}$. One clinically approved formulation of oral cyclosporin A, Neoral ${ }^{125}$, is based on a self-nanoemulsifying drug delivery system (SNEDDS) formulation that enhances bioavailability by controlling the dispersion size of the surfactant-cyclosporin A complex, thus directly improving the solubility of hydrophobic cyclosporin $\mathrm{A}^{126}$. In this case and in other cases with highly hydrophobic biologics such as cyclosporin $\mathrm{A}^{127}$, the surfactant is used to improve solubility to increase the interactions between the drug and the intestinal epithelium. Novel genetic engineering approaches that use living bacteria that have the machinery to synthesize and secrete biologics (for example, interleukin-10) have been tested in clinical trials ${ }^{128}$. This approach is similar to the living drug factories described above for subcutaneous delivery. Importantly, for all these examples, capsules are an enabling platform for the oral delivery of biologics, 
as they afford the freedom to simultaneously include several of these seminal advances in a single package that also provides protection and controlled-release capabilities.

Recent preclinical strategies. Several approaches including nanoparticles, mucoadhesive modifications, intestinal patches, hydrogels, peptide modifications and permeation enhancers - have been developed to enhance the oral delivery of biologics ${ }^{129}$ (FIG. 3b). Devices that physically disrupt the intestinal barrier to facilitate biologic transport have also been described. Rani Therapeutics has developed an approach to administer an intestinal injection to bypass the above challenges and deliver biologics. The intestinal injection device is shielded within a standard oral capsule and coated with enteric polymers. Once the microneedles are exposed to enteric $\mathrm{pH}(>6)$, the coating dissolves and the microneedles are exposed and penetrate the intestinal epithelium. This approach effectively avoids biologic interactions with digestive enzymes and other chemical challenges. It is possible that future microneedle devices can use external stimuli for controlled delivery. Similar technologies have been described in preclinical academic work. In one study, a microneedle capsule was designed to pierce gastrointestinal tissue and deliver biologics. Although the microneedle capsule was not directly evaluated for insulin delivery, it was shown that gastrointestinal injections of insulin exhibited higher bioavailability than standard subcutaneous injections in pigs. This established the proof of concept for oral microneedle delivery. Importantly, this study demonstrated that this device was safe; no evidence of tissue damage was observed, even in a case where the microneedle remained in the gastrointestinal tract for nearly 2 months ${ }^{130}$. These systems offer many of the same biological breaching advantages that transdermal microneedle systems offer; however, these systems are still in their infancy and will require further optimization and validation.

Other approaches have described novel mucoadhesive patches that bind to the intestinal mucus, prolong the residence time and localize biologics near or at the mucosal interface to enable unidirectional diffusion through the intestinal cells ${ }^{131,132}$ (FIG. 3b). As such, intestinal patches can be used to overcome many of the biological barriers that limit intestinal absorption of biologics. Depending on the size of the patches, they can be included in standard capsules and thus protected from the harsh gastrointestinal conditions in the stomach and elsewhere. The substantial efforts towards identifying mucoadhesive polymers ${ }^{133-135}$, chemical or permeation enhancers ${ }^{123,136-138}$ as well as biologic candidates for intestinal absorption ${ }^{139-141}$ can be leveraged for patch design. For example, patches that utilize mucoadhesive polymers and a chosen biologic in a matrix can ensure rapid release at the mucosal interface ${ }^{142}$. Higher concentrations of biologics at the interface can be achieved by controlling loading in the patch; this will improve diffusion by creating a high-concentration reservoir at the absorptive interface and therefore a large diffusional gradient. By virtue of a drug-polymer matrix system, permeation enhancers can be included to increase absorption ${ }^{143}$, thereby improving biologic transport. Furthermore, enteric capsules facilitate biologic protection against harsh gastrointestinal conditions at the desired duodenal site of intestinal absorption ${ }^{144}$. Other patch systems based on hydrogels ${ }^{145}$ have a rich history in $\mathrm{pH}$-responsive oral drug delivery for controlled release $\mathrm{e}^{146-148}$. Controlled-release approaches can be used to normalize dosing issues that stem from the heterogeneous gastrointestinal environment. Backing layers on the lumenal side can enable unidirectional diffusion towards the epithelium while also preventing interactions between the biologic and lumen contents (such as food, bile and enzymes) ${ }^{131,132}$. Some patch systems can be made using mass-production manufacturing approaches ${ }^{149}$ or can include multiple drug reservoirs either for combination therapy or inclusion of excipients (for example, chemical enhancers $)^{150}$. Efforts focused on the inclusion of excipients designed to improve storage of heat-sensitive or moisture-sensitive biologics may be the next step in patch development. In any case, patch-based oral delivery systems are extremely versatile ${ }^{151}$. Much like established transdermal patch systems, intestinal patch systems can offer an additive effect wherein design features that individually improve biologic delivery can be included simultaneously in a single system. Depending on the biologic of interest, intestinal patch systems can be used to confer protection and control dosing, thereby dictating efficacy. Recently, the ionic liquid transdermal technology described above has been successfully used in preclinical models to orally deliver insulin ${ }^{152}$.

Although particle-based delivery systems are mostly considered in the clinic for intravenous applications (in the case of nanoparticles ${ }^{153,154}$ ) or subcutaneous applications (in the case of microparticles ${ }^{7,155}$ ), approaches have also been described for oral delivery. The primary advantages that particle-based systems provide are protection of biologics from gastrointestinal environments and control of interactions with intestinal physical barriers (FIG. 3). Protection can typically be addressed using standard capsules, but controlling interactions on the molecular scale provides a separate, large and diverse toolbox to use to breach biological barriers in the gastrointestinal tract. In recent work, strategies to facilitate receptor-mediated translocation across the intestinal epithelium have highlighted the potential for nanoparticle-based oral delivery of biologics. In that study, a molecular targeting approach was used to navigate the intestinal barrier. By targeting specific receptors (the neonatal Fc receptor) on intestinal cells, active transport through the intestinal barrier could be achieved to enable systemic delivery of insulin ${ }^{156}$. In addition to antibody-based targeting, other approaches such as targeting peptides ${ }^{157}$, cell-penetrating peptides ${ }^{158}$ or aptamers ${ }^{159}$ and optimization of the physicochemical properties (for nanoparticles) ${ }^{160}$ could also be used to improve targeting or transport. Major preclinical efforts have described ways to improve the mucosal penetration of nanoparticles ${ }^{161-163}$, thus increasing the interaction 
with intestinal cells residing below. By increasing the fraction of nanoparticles that arrive at the intestinal epithelial barrier, transport into systemic circulation or enhanced diffusion, resulting from decreasing the diffusional path, could be achieved. These approaches rely on hydrophilic polymer coatings (such as polyethylene glycol) on the surface of nanoparticles; thus, it is unlikely that this modification would interfere with biologic loading or release. Importantly, these nanoparticle approaches can be combined in a single system; precedence for this approach comes from the multifunctional nanoparticles for intravenous applications that have already entered clinical trials ${ }^{164}$. Combining multiple advantages in one system could be leveraged to design oral nanoparticle delivery systems that can address multiple biological barriers and physiological challenges.

Snapshot of current clinical trials. Over 20 biologics are being clinically investigated for oral delivery (TABLE 4). Five peptides (octreotide for acromegaly, semaglutide for diabetes, insulin for diabetes, salmon calcitonin for osteoporosis and desmopressin for diabetes) are in phase III trials, and four vaccines (against Vibrio, cholera, typhoid and rotavirus) have been clinically approved and are in clinical use. The peptides being clinically investigated for oral delivery are all currently approved for use via injections, which has implications for regulatory approval - peptides previously approved for other routes of administration have a history of successful approvals and safe and efficacious use in the clinic.

The delivery of insulin dominates the oral delivery of biologics space. Other predominant biologics are for oral vaccinations, although the majority of current trials are for oral versions of approved vaccines for rotavirus, typhoid or cholera. Importantly, these diseases affect the gastrointestinal tract, which, considering mucosal immunity ${ }^{165}$, likely influences the desire to develop oral formulations for them. Of all the non-invasive routes of biologic administration highlighted in this article, oral delivery has the most current

Table 4 | Current trials and approved products for the oral delivery of biologics

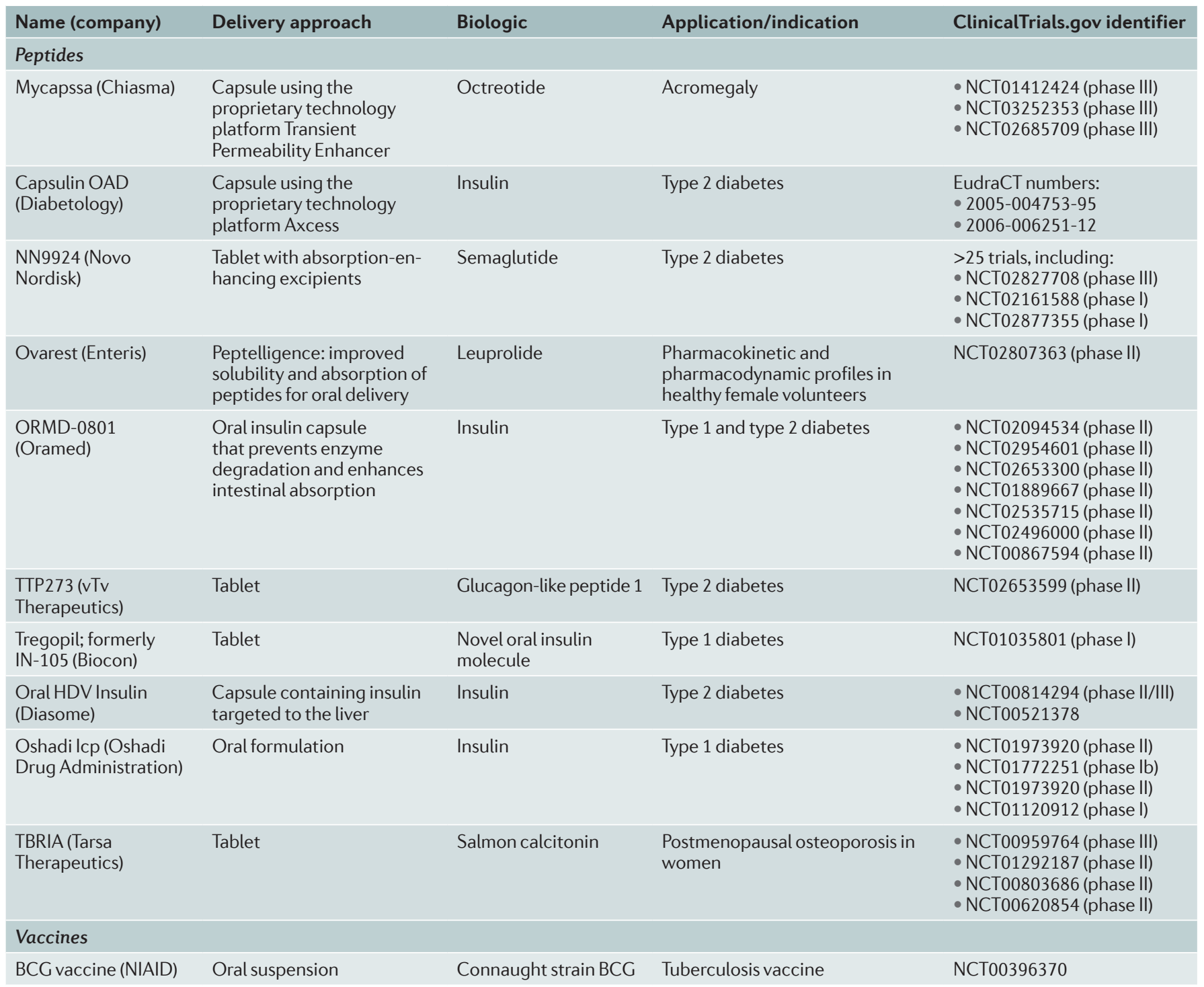


clinical trials. The indications for protein and antibody delivery include the treatment of inflammatory bowel disease (IBD), ulcerative colitis, hepatitis $\mathrm{C}$ infection, respiratory infections, coeliac disease and pulmonary fibrosis. A few of these proteins are for local delivery and treatment (colitis and IBD, for example), whereas the majority of the proteins are for systemic delivery. As with peptides, many of the current oral trials for proteins are focused on delivering commercially available biologics via the oral route. The goal here is to avoid injections altogether, highlighting the need for efficacious non-invasive delivery approaches. The main strategy for enabling oral biologic delivery in current clinical trials is to combine a standard capsule or enteric capsule with both enzymatic inhibitors and permeation enhancers in a single formulation. As described previously, the enteric capsule will allow the biologic to bypass the harsh stomach conditions and provide a means to control spatial release (in the duodenum). Enzyme inhibitors can be used to prevent enzymatic degradation by lumenal enzymes ${ }^{166,167}$. Finally, the permeation enhancer facilitates breaching of the biological barrier. Many current trials are focused on approaches that combine enzyme inhibitors with absorption enhancers. These strategies are being explored by Emisphere (Eligen technology), Diabetology (Axcess oral delivery system), Oramed and several others. In a late-stage example, Chiasma explored a proprietary Transient Permeability Enhancer (based on

Table 4 cont. | Current trials and approved products for the oral delivery of biologics

\begin{tabular}{|c|c|c|c|c|}
\hline Name (company) & Delivery approach & Biologic & Application/indication & ClinicalTrials.gov identifier \\
\hline \multicolumn{5}{|l|}{ Proteins } \\
\hline $\begin{array}{l}\text { AVX-470 (Avaxia } \\
\text { Biologics) }\end{array}$ & $\begin{array}{l}\text { Delayed-release } \\
\text { enteric-coated capsules } \\
\text { (releasing at } \mathrm{pH} 6.0 \text { ) }\end{array}$ & $\begin{array}{l}\text { Polyclonal } \\
\text { bovine-derived } \\
\text { antitumour necrosis } \\
\text { factor antibody }\end{array}$ & Inflammatory bowel disease & NCT01759056 (phase I) \\
\hline $\begin{array}{l}\text { OKT3 (Brigham and } \\
\text { Women's Hospital) }\end{array}$ & Oral delivery & $\begin{array}{l}\text { Muromonab } \\
\text { (monoclonal antibody } \\
\text { approved in 1985) }\end{array}$ & Ulcerative colitis & NCT01287195 (phase I/II) \\
\hline TAO1 (Theranos) & Tablet & $\begin{array}{l}\text { TAO1, oral } \\
\text { homeopathic } \\
\text { antibodies under trade } \\
\text { name Contaflu }\end{array}$ & Upper respiratory tract infections & NCT01651715 (phase I/II) \\
\hline $\begin{array}{l}\text { aCD3 (Inspira } \\
\text { Medical) }\end{array}$ & Oral delivery & $\begin{array}{l}\text { Anti-CD3 monoclonal } \\
\text { antibody }\end{array}$ & Hepatitis C & NCT01459419 (phase II) \\
\hline $\begin{array}{l}\text { Interferon- } \alpha \text { (Texas } \\
\text { Tech) }\end{array}$ & Oral lozenge & Interferon- $\alpha$ & Idiopathic pulmonary fibrosis & NCT01442779 (phase II) \\
\hline \multicolumn{5}{|c|}{ FDA-approved peptides } \\
\hline $\begin{array}{l}\text { DDAVP (Ferring } \\
\text { Pharmaceuticals) }\end{array}$ & Tablet & Desmopressin & $\begin{array}{l}\text { Antidiuretic replacement therapy } \\
\text { for diabetes insipidus }\end{array}$ & $\begin{array}{l}\text { >85 trials, including: } \\
\text { - NCT03051009 (phase III) } \\
\text { - NCT02636387 (phase III) }\end{array}$ \\
\hline \multirow{2}{*}{$\begin{array}{l}\text { Neoral (Novartis), } \\
\text { Sandimmune } \\
\text { (Novartis) }\end{array}$} & \multirow[t]{2}{*}{ Capsule with surfactants } & \multirow[t]{2}{*}{ Cyclosporin A } & \multirow[t]{2}{*}{ Organ rejection prophylaxis } & $\begin{array}{l}>250 \text { trials for oral } \\
\text { cyclosporine, including: }\end{array}$ \\
\hline & & & & $\begin{array}{l}\text { - NCT02706470 (phase II) } \\
\text { - NCT00977977 (phase II) }\end{array}$ \\
\hline \multicolumn{5}{|c|}{ FDA-approved vaccines } \\
\hline $\begin{array}{l}\text { Rotarix } \\
\text { (GlaxoSmithKline) }\end{array}$ & Oral suspension & $\begin{array}{l}\text { Live, monovalent, } \\
\text { human attenuated } \\
\text { rotavirus strain }\end{array}$ & $\begin{array}{l}\text { Prevention of rotavirus } \\
\text { gastroenteritis }\end{array}$ & $>50$ trials \\
\hline RotaTeq (Merck) & Oral suspension & $\begin{array}{l}\text { Live, pentavalent, } \\
\text { bovine attenuated } \\
\text { rotavirus strain }\end{array}$ & $\begin{array}{l}\text { Prevention of rotavirus } \\
\text { gastroenteritis }\end{array}$ & $>40$ trials \\
\hline
\end{tabular}

BCG, Bacillus Calmette-Guérin; NIAID, National Institute of Allergy and Infectious Diseases. 
sodium caprylate) that improved enzymatic resistance of the biologic while simultaneously enhancing permeation by disrupting epithelial tight junctions. FDA approval has been granted for the oral delivery of the peptide desmopressin and vaccines against cholera, salmonella and rotavirus; these approved indications continue to be investigated in many clinical trials (over 100 are investigating vaccines, and over 80 are investigating desmopressin).

Critical analysis and future challenges. Approaches that combine the traditional advantages of capsules with both permeation enhancers and protease-inhibiting or enzyme-mitigating compounds are among the most commonly explored oral delivery strategies. These approaches often use biologics that are approved through injectable routes, likely in an effort to expedite approval. Of the current studies, the majority are focused on diabetes treatment, as non-invasive insulin delivery has long been one of the active targets in the field of drug delivery. One common theme between oral biologic trials and preclinical work is the use of traditional dosage forms for formulation packaging. The advantages of this are twofold: the established protective benefits of capsules can be used to encapsulate these newer technologies, and patients are familiar with this dosage form. Examples of approved, orally delivered peptides exist; however, many of these examples still have formulation challenges. For example, Minirin, the orally administered version of desmopressin acetate, is a peptide that has low manufacturing costs and high potency ${ }^{168}$. As such, modifications to the peptide structure were sufficient to enable a bioavailability of $0.16 \%$, which is not high enough for most biologics but were sufficient for Minirin. Taltirelin, another approved, orally available biologic, is a highly stable peptide that requires limited formulation to achieve therapeutic levels of bioavailability ${ }^{168}$. Other examples of approved peptides for oral delivery, such as cyclosporin A and antimicrobial biologics, have been reviewed elsewhere ${ }^{168}$. Another approach, which builds on the recent interest in the microbiome and clinically used bacteria-based therapeutics ${ }^{128}$, utilizes genetically engineered bacteria to deliver biologics. The clinical applications of these approaches have been for local delivery and have been reviewed elsewhere ${ }^{169}$; however, it may be possible to leverage genetically engineered bacteria to secrete drugs, enzyme inhibitors or absorption enhancers to facilitate systemic absorption. Living drug factories may provide benefits that non-living systems cannot, such as their capacity to establish permanent or semi-permanent colonization or their natural ability to navigate the mucus and interact with intestinal cells.

Pulmonary surfactant Lipid and protein secreted by type II alveolar cells that adsorb to the air-water interface in the lungs. Pulmonary surfactant is a required biological fluid that reduces the surface tension in lung alveoli to facilitate inhalation and exhalation.

\section{Inhalation delivery}

The inhalation route has been actively pursued for the delivery of proteins and peptides ${ }^{170}$ because of the large surface area and extensive vascularization in the lungs that can enable rapid systemic absorption. Like the other highlighted routes, the inhalation route is non-invasive and can offer advantages such as patient compliance and self-administration; furthermore, inhalation approaches can use existing nebulization or inhaler-based delivery devices.

Fundamental barriers. The inhalation route poses several delivery hurdles (FIG. 4a). The first and most important hurdle is the penetration of inhaled drugs deep into the lungs. Size, shape, porosity, density and many other physical parameters of the inhaled biologic or formulation will influence deposition and distribution, and thus absorption, in the lungs ${ }^{171}$. Much of the past work has focused on determining the optimal formulation characteristics to ensure appropriate lung deposition, and this optimization would be formulation-specific because biologics require individualized optimization for stability, loading and dosing. Following deposition in the deep lung, delivered biologics will first encounter pulmonary surfactant ${ }^{172}$. This presents a transport challenge, similar to that previously described for delivery through the lipid bilayers in the stratum corneum. In addition to these challenges, the pulmonary surfactant must not be disturbed during delivery or respiratory problems could result ${ }^{173}$. Alveolar macrophages, which are in close proximity to the pulmonary surfactant, must also be avoided. Pulmonary macrophages will internalize, sequester and clear biologics before they reach systemic circulation ${ }^{174}$; the presence of immunoglobulin G (IgG) in both pulmonary surfactant and pulmonary mucus facilitates and accelerates macrophage-mediated clearance ${ }^{175}$. Indeed, sections of the lung contain pulmonary mucus, and as described in the oral delivery section, diffusion across the mucosal barrier and strategies to overcome mucus turnover and clearance must be considered ${ }^{161}$. Enzymes can also be encountered in the lungs, which can degrade biologics, thus limiting delivery ${ }^{170}$. A few of these challenges overlap with those in other tissues, but the need to mutually and preferentially consider lung deposition and distribution is a key hurdle.

Seminal advances to overcome barriers in the clinic. Devices that enable the inhalation and delivery of drugs have spurred interest in inhalable biologic delivery. Inhalers include metered dose inhalers, nebulizers and dry powder inhalers ${ }^{176}$. Metered dose inhalers were originally developed in the $1950 \mathrm{~s}^{177}$ and facilitated the controlled delivery of specific amounts of drugs to the lungs. This invention ${ }^{178}$, along with the ability to control delivery, deeply affected the field of pulmonary drug delivery. Today, these systems are mostly used to deliver medications to treat asthma or chronic obstructive pulmonary disease. Typically, nebulizers and metered dose inhalers use aqueous suspensions, which are not ideal for biologic storage; as such, dry powder inhalers ${ }^{179}$ are used for the most successful inhaled biologic products. Formulating drug powders ${ }^{180}$ is therefore the first requirement to enable delivery of biologics to the lung. Many drug powders for inhalation are particulate drug carriers ${ }^{172}$. Various synthesis approaches - including spray drying, milling, lyophilization, freeze drying and other atomization methods - afford the freedom to optimize formulation parameters during synthesis ${ }^{181}$. Seminal preclinical work 

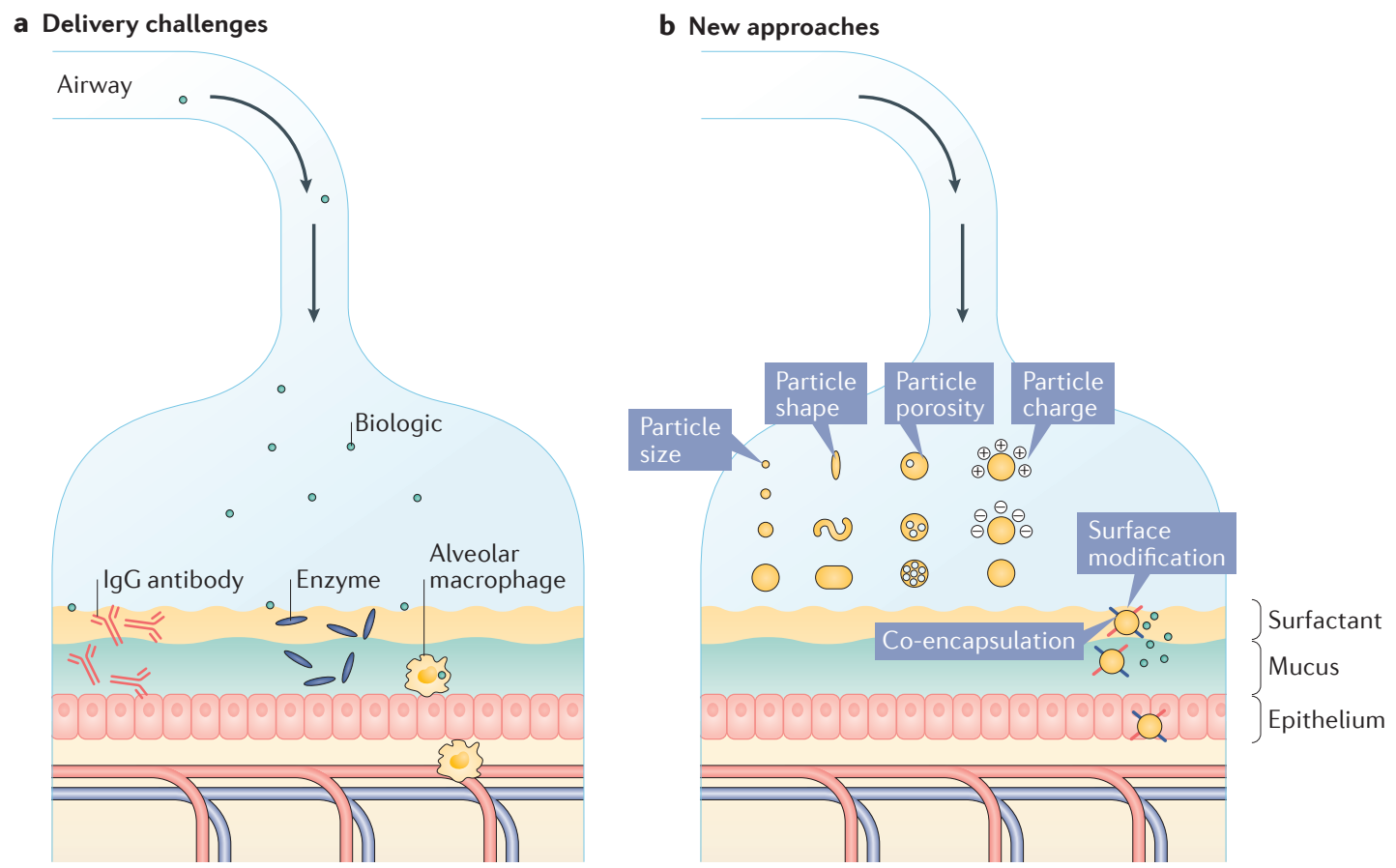

Figure 4 | Inhalable barriers, products and new approaches. a | Delivery barriers that limit biologic transport and absorption via the inhalation route. The physiology of the lung prevents the arrival and distribution of inhaled drugs or drug particles. Immunoglobulin $\mathrm{G}(\mathrm{lgG})$ antibodies present in the luminal layers act as opsonins, which leads to enhanced uptake by alveolar macrophages and subsequent clearance. Enzymes degrade biologics before absorption. $\mathbf{b} \mid$ Approaches to alter the physical characteristics of particles and their formulations enable suitable airway transport of formulated biologics to lung absorption sites. Particle size and physicochemical properties dictate surfactant and mucus diffusion and epithelial cell internalization. Physical alterations include changing the size, shape, porosity and charge of the particle. Formulation approaches include particle surface modifications to prevent interactions with antibodies, enzymes or macrophages. Co-encapsulation of permeation or transport enhancers can also be used to disrupt cell barriers

described the roles that particulate density, porosity, shape, size, charge, release rate and flowability play in the lung deposition and systemic absorption of drugs ${ }^{180,182-184}$ (FIG. 4b). These early findings set the standard in particle design for pulmonary biologic delivery and simultaneously inspired the development of approaches to evaluate inhalation formulations ${ }^{185,186}$.

Two products in particular have made substantial progress for the inhalable delivery of biologics: Pfizer's Exubera and, more recently, MannKind's Afrezza ${ }^{187}$. Exubera used a dry powder inhaler, which improved the stability and storage of insulin and optimized aerosol characteristics to facilitate suitable dispersion, delivery and absorption ${ }^{188}$. The successful clinical trials for Exubera ${ }^{189-191}$ led to FDA approval in 2006 (REF. ${ }^{192}$ ). However, after being clinically available and on the market for 1 year, Exubera was discontinued ${ }^{192}$ for reasons ${ }^{193,194}$ including the high cost ${ }^{195}$, concerns with side effects such as lung cancer ${ }^{187}$ and the large size of the inhaler ${ }^{196}$. Other inhalable insulin technologies (the AIR system by Alkermes or the AERx system, which was licensed to Novo Nordisk) were discontinued during phase III trials in 2008, likely because of the withdrawal of Exubera ${ }^{197}$. More recently, in 2014, MannKind's Afrezza received FDA approval for the inhalable delivery of insulin based on clinical trial data ${ }^{197}$. Afrezza is still in active clinical trials (TABLE 5) and is marketed for inhalable insulin delivery. Thorough analyses have been published comparing Exubera and Afrezza, specifically discussing the potential Afrezza has in achieving commercial success, perhaps through implementing lessons learned from Exubera's discontinuation ${ }^{7,187,198}$. For example, better commercial success of Afrezza over Exubera could arise from Afrezza's smaller size, increased user-friendliness (that includes packaging with standard insulin dosing units $)^{187}$ and favourable pharmacokinetic profile that mimics endogenous insulin ${ }^{198}$. It is also worth mentioning the successful local delivery of peptide-containing or protein-containing lung surfactants (for example, Survanta, Infasurf and Curosurf) for the treatment of neonatal or infant respiratory distress syndrome ${ }^{199,187}$. Although these products are administered intratracheally, they have established the delivery of biologically sourced peptides and proteins to the lungs for local action.

Recent preclinical strategies. As with oral delivery, particle-based approaches can afford molecular-level control over interactions between the particles and the lung. Particle-based systems can leverage existing knowledge of lung deposition and subsequent absorption ${ }^{170}$. Indeed, modification of particle platforms to control their microenvironmental interactions is the most active area of preclinical research to overcome systemic lung delivery barriers ${ }^{200}$. Strategies used in other 
Table 5 | Current trials and approved products for the inhalation delivery of biologics

\begin{tabular}{|c|c|c|c|c|}
\hline Name (company) & Delivery approach & Biologic & Application/indication & ClinicalTrials.gov identifier \\
\hline \multicolumn{5}{|l|}{ Peptides } \\
\hline $\begin{array}{l}\text { Dance } 501 \\
\text { (Dance Biopharm) }\end{array}$ & $\begin{array}{l}\text { Inhaler (insulin in } \\
\text { liquid) }\end{array}$ & Human insulin & $\begin{array}{l}\text { Pharmacokinetic and } \\
\text { pharmacodynamic profiles of } \\
\text { Dance } 501 \text { in healthy subjects } \\
\text { without diabetes but with mild to } \\
\text { moderate asthma or COPD }\end{array}$ & $\begin{array}{l}\text { - NCT03307512 (phase I) } \\
\text { - NCT02716610 (phase I/II) } \\
\text { - NCT02713841 (phase I/II) }\end{array}$ \\
\hline \multicolumn{5}{|l|}{ Vaccines } \\
\hline PUR003 (Pulmatrix) & Nebulizer & Not listed & Flu vaccine & NCT00947687 (phase I) \\
\hline $\begin{array}{l}\text { Ad5Ag85A (McMaster } \\
\text { University) }\end{array}$ & Aerosol & $\begin{array}{l}\text { Recombinant replication- } \\
\text { deficient human adenoviral } \\
\text { tuberculosis vaccine } \\
\text { containing immunodominant } \\
\text { antigen Ag85A }\end{array}$ & Tuberculosis vaccine & NCT02337270 (phase I) \\
\hline Exubera (Pfizer) & $\begin{array}{l}\text { Inhaled through } \\
\text { mouth }\end{array}$ & Human insulin & $\begin{array}{l}\text { Approved indication: diabetes } \\
\text { mellitus }\end{array}$ & $\begin{array}{l}\text { >20 trials (none active), } \\
\text { including: } \\
\text { - NCT00734591 } \\
\text { - NCT00359801 (phase IV) }\end{array}$ \\
\hline Afrezza (MannKind) & $\begin{array}{l}\text { Inhaled through } \\
\text { mouth }\end{array}$ & Human insulin & $\begin{array}{l}\text { Approved indication: diabetes } \\
\text { mellitus }\end{array}$ & $\begin{array}{l}\text { >50 trials, including: } \\
\text { - NCT02527265 (phase II) } \\
\text { - NCT03324776 (phase III) } \\
\text { - NCT03313960 (phase IV) }\end{array}$ \\
\hline
\end{tabular}

COPD, chronic obstructive pulmonary disease.

areas of particle-based drug delivery are also being investigated ${ }^{201}$. For example, mucopenetrative and mucoadhesive methods to increase retention time or diffusion have been considered ${ }^{200}$. Chemical or permeation enhancers such as surfactants, polymers and sugars are being investigated to aid in the transport of biologics across the epithelial barrier in the lungs $\mathrm{s}^{202}$. Cell-penetrating peptides ${ }^{203}$ may also improve biologic transport via the mechanisms described previously. Other efforts focus on optimizing excipient ratios to stabilize the biologic during processing and storage, to prevent biologic aggregation and to ensure suitable dispersion once the particle begins to solubilize. These efforts may lead to the development of nebulized approaches, as storage of biologics in liquids remains a limiting challenge ${ }^{81}$. The use of enzyme or protease inhibitors to prevent premature digestion of the biologic has also been shown to improve delivery ${ }^{204}$. Areas of research that can potentially address current systemic absorption challenges in the lungs may include the development of formulations that contain targeting ligands or hydrophilic coatings to avoid macrophage uptake, or that have mucoadhesive or mucopenetrative abilities (FIG. 4b).

Snapshot of current clinical trials. Current clinical trials for the inhalation delivery of biologics focus on insulin or vaccines (TABLE 5). Over 50 trials exist for the FDAapproved inhalable insulin Afrezza. For the previously discontinued inhalable insulin, Exubera, the previous trials $(>20)$ and their details can still be accessed. Other trials for inhalable insulin include Dance 501, which is a stable liquid insulin formulation with a pocket-sized inhalation device. The liquid formulation is distinct from the dry powder inhalable insulins, Afrezza and Exubera. Inhalable vaccines for the flu, via nebulizer, and tuberculosis, via aerosol, are also being investigated in clinical trials. As with oral vaccines, there may be advantages related to mucosal immunity if lung delivery is used for these vaccines ${ }^{165}$. A recently completed clinical trial from MannKind investigated the inhalation of human parathyroid hormone for the treatment of osteoporosis. Other completed clinical trials have tested the inhalation of human growth hormone (Alkermes and Eli Lilly), interleukin-2 for pulmonary metastases and immunodeficiency, an erythropoietin-Fc fusion protein for anaemia, heparin for thrombus prevention, oxytocin for postpartum haemorrhage and calcitonin for osteoporosis. These trials are either completed or being explored for local delivery and hence are not listed in TABLE 5. This broad range of indications highlights the potential of inhalable biologics. Importantly — although not covered in depth here - there are many active, late-stage (for example, phase II/III) trials investigating the lung delivery of proteins and peptides for local lung delivery. Examples include Kamada's inhalable a1-antitrypsin formulation for the treatment of emphysema (phase II/III), Grifols' nebulizer-delivered prolastin ( $\alpha 1$-antitrypsin) for the treatment of cystic fibrosis and Bayer's phase II study for the local delivery of interleukin- 4 for asthma treatment, to name a few. 
Critical analysis and future challenges. One of the main challenges in the field is overcoming the past withdrawal and discontinuation of Exubera and other late-stage inhaled insulins (for example, AERx and AIR). Although these products set the standard for the inhalation of biologics, they also raised considerable doubt as to whether or not inhalable insulin delivery is a commercially viable long-term product. This is an important consideration because the majority of current efforts are focused on inhalable insulin. Few novel devices are being developed for inhalation delivery simply because inhalable devices currently exist (such as dry powder inhalers) and, much like the capsule for oral delivery, these devices are the gold standard for inhalation. As such, the overwhelming majority of efforts focus on optimizing current device-compatible platforms, such as particle-based formulations, or combining various approaches to overcome delivery challenges.

\section{Nasal and buccal delivery}

Nasal and buccal delivery has been actively pursued for peptide delivery owing to the relatively easy access and high permeability of the mucosal membrane compared with other tissues ${ }^{205}$. To date, many approved and clinically studied biologics for non-invasive delivery utilize the buccal or nasal administration route.

Fundamental barriers. Nasal and buccal delivery routes have substantial transport barriers, somewhere between those posed by the skin and the intestine in terms of severity ${ }^{206}$. Like the intestinal mucus, the nasal and buccal mucosal surfaces can limit what reaches the absorptive cells and thus what enters systemic circulation. For both buccal and nasal delivery, biologic transport across the mucosal and epithelial layers (which is up to $800 \mu \mathrm{m}$ thick for the buccal route ${ }^{207}$ ) must occur to enable systemic absorption. The epithelial layer, specifically the unique lipid content of the buccal epithelium, poses the greatest issue $\mathrm{e}^{81}$. Limitations unique to nasal delivery are predominately related to the low surface area available for delivery, which limits dosing and absorption and thus therapeutic efficacy. Other, non-barrier challenges that specifically limit buccal delivery relate to taste ${ }^{208}$ and the potential for the biologic to be diluted by saliva or even swallowed and delivered orally ${ }^{209}$. Issues that limit absorption and are common to other delivery routes include the irritation that can occur at mucosal surfaces ${ }^{209}$, the limited surface area available for transport ${ }^{209}$, the presence of degrading enzymes at the mucosal surface (more prevalent for the nasal surface $)^{210}$ and the potential for microorganisms to interact with the delivered biologic, as has been recently shown for other mucosal surfaces and drugs ${ }^{211}$. Delivery via the sublingual route also occurs at the oral mucosal interface. Sublingual administration occurs under the tongue and is distinct from buccal administration, which occurs on the inner cheek. It should be noted that although therapies can be absorbed extremely rapidly via the sublingual route, it is less investigated as a route of administration for biologics than the buccal route ${ }^{81}$ and thus is not highlighted in depth here.
Seminal advances to overcome barriers in the clinic. Spray-based approaches dominate the clinical landscape for biologics delivered through the nasal route. Sprays have been developed to enable rapid absorption when applied to the nasal ${ }^{212}$, and to a lesser extent the buccal, membrane surfaces. Sprays rely on absorption by the vascular mucous membrane in the nose, can be self-administered and offer rapid onset of action ${ }^{213}$. One of the main advantages of sprays is that they disperse and spread on mucosal surfaces on the nasal or oral cavity, and thus absorption can readily occur. Many nasal sprays have been approved for the delivery of biologics, such as DDAVP for the delivery of desmopressin, Miacalcin for the delivery of calcitonin, Syntocinon for the delivery of oxytocin and Synarel for the delivery of nafarelin, all via nasal spray. A flu vaccine, FluMist Quadrivalent, has also been approved as a nasal spray (TABLE 6).

Recent preclinical strategies. Similar to other tissues that require epithelial transport, permeation enhancers are widely investigated for improving biologic transport in buccal ${ }^{214}$ and nasal ${ }^{215}$ routes. Other approaches utilize surfactants or bile salts to aid in the solubilization and extraction of lipids from the buccal tissue to enable transport of biologics through the paracellular route ${ }^{216}$. Fatty acids have been used to reduce lipid packing between epithelial cells to improve biologic absorption ${ }^{217}$. Mucoadhesive delivery technologies are used to interface the biologic with the mucosal surface to control contact and delivery times ${ }^{218}$. Efforts to extend the contact time between the biologic and the absorption site focus on the use of mucoadhesive polymers to maintain the biologic at the mucosal surface; these advantages were previously described for other tissues, and the same advantages apply to the buccal and nasal routes. The contact time can be extended either directly by increasing absorption by modulating the epithelial barrier or indirectly by prolonging residence time with high-concentration reservoirs. Current preclinical efforts focus on developing and evaluating novel additions to these established approaches. For example, most continued efforts focus on discovering or engineering novel permeation enhancers and mucoadhesive polymers ${ }^{206,219}$. Nanoparticle-based systems, as highlighted in all previous sections, offer superb control over the molecular interactions with the mucus and epithelium and are being investigated for buccal and nasal delivery to improve biologic absorption through targeted, improved navigation through the mucus and improved biologic stability ${ }^{220}$.

Snapshot of current clinical trials. Numerous approved uses for biologics utilize the buccal and nasal routes (TABLE 6). Currently investigated buccal formulations include mucoadhesive films, sprays and nanoparticles for insulin delivery. Multiple early stage (phase I or phase II) vaccines (for example, those for tuberculosis, syncytial virus, HIV, Sendai virus or flu) are being developed for nasal delivery. These nasal formulations are all liquid-based and are delivered either as sprays or drops. 
Table 6 | Current trials and approved products for the nasal or buccal delivery of biologics

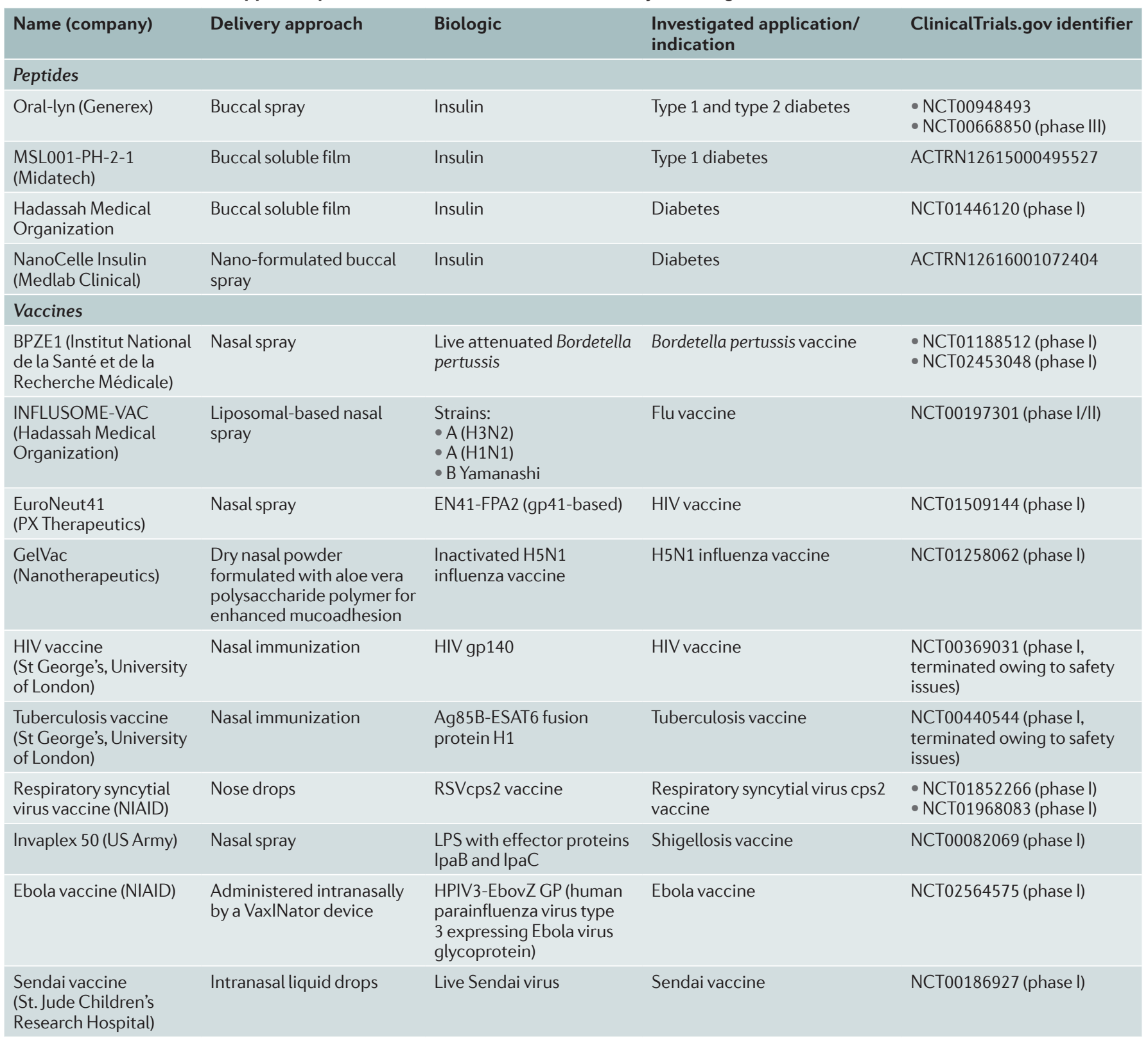

Critical analysis and future challenges. Many of the same approaches (such as permeation enhancers and mucoadhesion) used for other mucosal and epithelial barriers are used for nasal and buccal delivery, but they are limited by the low surface area relative to the transdermal route. Despite the comparable accessibility and ease of administration between transdermal and buccal or nasal mucosal surfaces, preclinical and clinical efforts are comparatively lacking for the buccal and nasal routes. The buccal or nasal route is ideally suited for specific applications that occur preferentially at mucosal surfaces (such as vaccines). The nasal route can also make use of the connection from the nasal-accessible olfactory pathway to the brain ${ }^{221,222}$. Indeed, the clinical landscape, which is dominated by approved nasal sprays and currently investigated vaccines, indicates this may be the case. It is also clear that an opportunity to develop new approaches that have distinct mechanisms from traditional approaches (namely, mucoadhesive films and sprays) could exist. However, given the limited absorptive surface area, it is challenging to use the nasal or buccal routes to deliver the high doses required by many antibodies or proteins.

\section{Conclusion}

The rapid approval and use of biologics in the clinic have led to a shift in how these drugs are delivered. This shift requires new delivery strategies as new challenges and unmet needs arise. These challenges include accounting for patient adherence, compliance and acceptance. 
Table 6 (cont.) | Current trials and approved products for the nasal or buccal delivery of biologics

\begin{tabular}{|c|c|c|c|c|}
\hline Name (company) & Delivery approach & Biologic & $\begin{array}{l}\text { Investigated application/ } \\
\text { indication }\end{array}$ & ClinicalTrials.gov identifier \\
\hline \multicolumn{5}{|c|}{ FDA-approved peptides } \\
\hline $\begin{array}{l}\text { DDAVP (Ferring } \\
\text { Pharmaceuticals) }\end{array}$ & Nasal spray & Desmopressin & $\begin{array}{l}\text { Approved indication: } \\
\text { antidiuretic replacement } \\
\text { therapy for diabetes insipidus }\end{array}$ & $\begin{array}{l}\text { >85 trials, including: } \\
\text { - NCT01280188 (phase III) } \\
\text { - NCT01742689 (phase III) }\end{array}$ \\
\hline Miacalcin (Novartis) & Nasal spray & Calcitonin & $\begin{array}{l}\text { - Approved indication: } \\
\text { symptomatic Paget disease } \\
\text { - Other indications: } \\
\text { postmenopausal osteoporosis } \\
\text { and fibromyalgia }\end{array}$ & $\begin{array}{l}\text { >10 trials, including: } \\
\text { - NCT00239889 (phase IV) } \\
\text { - NCT00754884 (phase IV) }\end{array}$ \\
\hline Syntocinon (Novartis) & Nasal spray & Oxytocin & $\begin{array}{l}\text { Approved indication: induction } \\
\text { of labour }\end{array}$ & $\begin{array}{l}\text { >100 trials, including: } \\
\text { - NCT01308749 (phase II) } \\
\text { - NCT02336568 (phase IV) }\end{array}$ \\
\hline Synarel (Pfizer) & Nasal spray & $\begin{array}{l}\text { Nafarelin (gonadotro- } \\
\text { pin-releasing hormone) }\end{array}$ & $\begin{array}{l}\text { - Approved indication: central } \\
\text { precocious puberty } \\
\text { - Other indications: embryo } \\
\text { replacement therapy and } \\
\text { endometriosis }\end{array}$ & $\begin{array}{l}\text { - NCT00843570 (phase IV) } \\
\text { - NCT00034047 (phase I/II) } \\
\text { - NCT00756028 (phase IV) }\end{array}$ \\
\hline \multicolumn{5}{|l|}{ FDA-approved vaccines } \\
\hline $\begin{array}{l}\text { FluMist Quadrivalent } \\
\text { (AstraZeneca) }\end{array}$ & Nasal spray & $\begin{array}{l}\text { Four strains of attenuated } \\
\text { live virus: } \\
\text { - } \mathrm{A}(\mathrm{H} 1 \mathrm{~N} 1) \\
\text { - } \mathrm{A}(\mathrm{H} 3 \mathrm{~N} 2) \\
\text { - B Yamagata lineage } \\
\text { - B Victoria lineage }\end{array}$ & Flu vaccine & $\begin{array}{l}\text { >10 trials, including } \\
\text { NCT03158038 (phase IV) }\end{array}$ \\
\hline
\end{tabular}

LPS, lipopolysaccharide; NIAID, National Institute of Allergy and Infectious Diseases.

As doses of biologics can span nearly an order of magnitude, versatile delivery technologies that are amenable to different volumes, preparations and even states of drugs will need to be designed. A major focus has been on identifying and evaluating excipients for storage, enhancing permeation and diffusion, and enabling prolonged residence time at the injection site to improve the absorption of biologics at biological barriers . This existing knowledge can accelerate the evaluation of novel devices and technologies by acting as a toolbox for new approaches. Of course, new non-invasive delivery strategies must be designed such that they are compatible with regulatory approved excipients: a consideration that could accelerate the translation of new delivery methods.
1. Leader, B., Baca, Q. J. \& Golan, D. E. Protein therapeutics: a summary and pharmacological classification. Nat. Rev. Drug Discov. 7, 21-39 (2008).

2. Fosgerau, K. $\&$ Hoffmann, T. Peptide therapeutics: current status and future directions. Drug Discov. Today 20, 122-128 (2015).

3. Singh, S. et al. Monoclonal antibodies: a review. Curr. Clin. Pharmacol. https://doi.org/10.2174/15748 84712666170809124728 (2017).

4. Hamman, J. H., Enslin, G. M. \& Kotzé, A. F. Oral delivery of peptide drugs. BioDrugs 19, 165-177 (2005).

5. Smith, P. L., Wall, D. A., Gochoco, C. H. \& Wilson, G (D) Routes of delivery: case studies:(5) Oral absorption of peptides and proteins. Adv. Drug Delivery Rev. 8 , 253-290 (1992).

6. Jin, J.-f. et al. The optimal choice of medication administration route regarding intravenous, intramuscular, and subcutaneous injection. Patient Prefer. Adherence 9, 923 (2015).

7. Anselmo, A. C. \& Mitragotri, S. An overview of clinical and commercial impact of drug delivery systems. J. Control. Release 190, 15-28 (2014).

8. Badylak, S. F. in Seminars in Cell and Developmental Biology Vol. 13, 377-383 (Elsevier, 2002).

9. Keizer, R. J., Huitema, A. D., Schellens, J. H. \& Beijnen, J. H. Clinical pharmacokinetics of therapeutic monoclonal antibodies. Clin. Pharmacokinet. 49 493-507 (2010).
10. Kagan, L., Turner, M. R., Balu-lyer, S. V. \& Mager, D. E. Subcutaneous absorption of monoclonal antibodies: role of dose, site of injection, and injection volume on rituximab pharmacokinetics in rats. Pharm. Res. 29 490-499 (2012)

11. Wang, W., Wang, E. \& Balthasar, J. Monoclonal antibody pharmacokinetics and pharmacodynamics. Clin. Pharmacol. Ther. 84, 548-558 (2008).

12. Vugmeyster, Y., Xu, X., Theil, F.-P., Khawli, L. A. \& Leach, M. W. Pharmacokinetics and toxicology of therapeutic proteins: advances and challenges. World J. Biol. Chem. 3, 73 (2012).

13. Turner, M. R. \& Balu-lyer, S. V. Challenges and opportunities for the subcutaneous delivery of therapeutic proteins. J. Pharm. Sci. 107, 1247-1260 (2018).

14. Fathallah, A. M., Bankert, R. B. \& Balu-lyer, S. V. Immunogenicity of subcutaneously administered therapeutic proteins - a mechanistic perspective. AAPS J. 15, 897-900 (2013).

15. Yasukawa, K., Sawamura, D., Sugawara, H. \& Kato, N. Leuprorelin acetate granulomas: case reports and review of the literature. Br. J. Dermatol. 152, 1045-1047 (2005)

16. Neely, E. et al. Two-year results of treatment with depot leuprolide acetate for central precocious puberty. J. Pediatr. 121, 634-640 (1992).

17. Ferran, M. et al. Depot leuprorelin acetate-induced granulomas manifested as persistent suppurative nodules. Acta Dermato-Venereol. 86, 453-455 (2006).
18. Toole, B. P. Hyaluronan: from extracellular glue to pericellular cue. Nat. Rev. Cancer 4, 528 (2004).

19. Chain, E. \& Duthie, E. Identity of hyaluronidase and spreading factor. Br. J. Exp. Pathol. 21, 324 (1940)

20. Frost, G. I. Recombinant human hyaluronidase (rHuPH20): an enabling platform for subcutaneous drug and fluid administration. Expert Opin. Drug Delivery 4, 427-440 (2007).

21. Duran-Reynals, F. Exaltation de l'activité du virus vaccinal par les extraits de certains organes. Compt Rend Soc. Biol. 9, 6-7 (1928).

This is one of the earliest published reports of using hyaluronidases to improve delivery of model small molecules (dyes) and biologics (viruses).

22. Girish, K. \& Kemparaju, K. The magic glue hyaluronan and its eraser hyaluronidase: a biological overview. Life Sci. 80, 1921-1943 (2007).

23. Kind, L. S. \& Roffler, S. Allergic reactions to hyaluronidase. Proc. Soc. Exp. Biol. Med. 106, 734-735 (1961).

24. Mathews, M. B. \& Dorfman, A. Inhibition of hyaluronidase. Physiol. Rev. 35, 381-402 (1955).

25. Schulmeister, L. Managing vesicant extravasations. Oncology 13, 284-288 (2008)

26. Wasserman, R. L. Recombinant human hyaluronidase-facilitated subcutaneous immunoglobulin infusion in primary immunodeficiency diseases. Immunotherapy $\mathbf{9}$ 1035-1050 (2017). 
27. Cui, Y., Cui, P., Chen, B., Li, S. \& Guan, H. Monoclonal antibodies: formulations of marketed products and recent advances in novel delivery system. Drug Dev. Industrial Pharmacy 43, 519-530 (2017).

28. Rosengren, S., Souratha, J., Conway, D. Muchmore, D. B. \& Sugarman, B. J. Recombinant human PH20: baseline analysis of the reactive antibody prevalence in the general population using healthy subjects. BioDrugs 32, 83-89 (2018).

29. Narasimhan, C., Mach, H. \& Shameem, M. High-dose monoclonal antibodies via the subcutaneous route: challenges and technical solutions, an industry perspective. Ther. Delivery 3, 889-900 (2012)

30. Wright, J. C. \& Hoffman, A. S. in Long Acting Injections and Implants 11-24 (Springer, 2012).

31. Dlugi, A. M., Miller, J. D. \& Knittle, J. Lupron depot (leuprolide acetate for depot suspension) in the treatment of endometriosis: a randomized, placebocontrolled, double-blind study. Fertil. Steril. 54 419-427 (1990)

32. Kappy, M., Stuart, T., Perelman, A. \& Clemons, R. Suppression of gonadotropin secretion by a longacting gonadotropin-releasing hormone analog (leuprolide acetate, Lupron Depot) in children with precocious puberty. J. Clin. Endocrinol. Metab. 69, 1087-1089 (1989)

33. Silverman, B. L. et al. A long-acting human growth hormone (Nutropin Depot ${ }^{\circledR}$ ): efficacy and safety following two years of treatment in children with growth hormone deficiency. J. Pediatr. Endocrinol. Metab. 15, 715-722 (2002).

34. Braeckman, J. \& Michielsen, D. Efficacy and tolerability of 1-and 3-month leuprorelin acetate depot formulations (Eligard ${ }^{\circledR} /$ Depo-Eligard ${ }^{\circledR}$ ) for advanced prostate cancer in daily practice: a Belgian prospective non-interventional study. Arch. Med. Sci. 10, 477 (2014).

35. Gefvert, O. et al. Pharmacokinetics and D2 receptor occupancy of long-acting injectable risperidone (Risperdal Consta ${ }^{\text {TMI }}$ ) in patients with schizophrenia. Int. J. Neuropsychopharmacol. 8, 27-36 (2005).

36. Dunbar, J. L. et al. Single- and multiple-dose pharmacokinetics of long-acting injectable naltrexone Alcohol. Clin. Exp. Res. 30, 480-490 (2006).

37. Ballav, C.\& Gough, S. Bydureon: long-acting exenatide for once-weekly injection. Prescriber 23, 30-33 (2012).

38. Mosekilde, E., Jensen, K. S., Binder, C., Pramming, S. \& Thorsteinsson, B. Modeling absorption kinetics of subcutaneous injected soluble insulin.

J. Pharmacokinet. Biopharmaceut. 17, 67-87 (1989)

39. Berger, M. \& Rodbard, D. Computer simulation of plasma insulin and glucose dynamics after subcutaneous insulin injection. Diabetes Care 12, 725-736 (1989)

40. Lacy, P. E., Hegre, O. D., Gerasimidi-Vazeou, A. Gentile, F. T. \& Dionne, K. E. Maintenance of normoglycemia in diabetic mice by subcutaneous xenografts of encapsulated islets. Science 254 1782-1784 (1991).

41. Vegas, A. J. et al. Long-term glycemic control using polymer-encapsulated human stem cell-derived beta cells in immune-competent mice. Nat. Med. 22, 306 (2016).

42. Vegas, A. J. et al. Combinatorial hydrogel library enables identification of materials that mitigate the foreign body response in primates. Nat. Biotechnol. 34,345 (2016).

43. Veiseh, O. et al. Size-and shape-dependent foreign body immune response to materials implanted in rodents and non-human primates. Nat. Mater. 14, 643 (2015)

44. Fan, M.-Y. et al. Reversal of diabetes in BB rats by transplantation of encapsulated pancreatic islets. Diabetes 39, 519-522 (1990)

45. Scharp, D. W. et al. Protection of encapsulated human islets implanted without immunosuppression in patients with type I or type II diabetes and in nondiabetic control subjects. Diabetes $\mathbf{4 3}$ 1167-1170 (1994)

46. Shapiro, A. J. et al. Islet transplantation in seven patients with type 1 diabetes mellitus using a glucocorticoid-free immunosuppressive regimen. N. Engl. J. Med. 343, 230-238 (2000)

47. Desai, T. \& Shea, L. D. Advances in islet encapsulation technologies. Nat. Rev. Drug Discov. 16, 338 (2017).

48. Cooper, D. K. et al. Progress in clinical encapsulated islet xenotransplantation. Transplantation 100, 2301 (2016).

49. Aghazadeh, Y. \& Nostro, M. C. Cell therapy for type diabetes: current and future strategies. Curr. Diabetes Rep. 17, 37 (2017).
50. Y. Li et al. In situ pneumococcal vaccine production and delivery through a hybrid biological-biomaterial vector. Sci. Adv. 2, e1600264 (2016).

51. Orive, G. et al. Cell encapsulation: promise and progress. Nat. Med. 9, 104 (2003).

52. Fliervoet, L. A. \& Mastrobattista, E. Drug delivery with living cells. Adv. Drug Delivery Rev. 106, 63-72 (2016)

53. Mura, S., Nicolas, J. \& Couvreur, P. Stimuli-responsive nanocarriers for drug delivery. Nat. Mater. 12, 991 (2013)

54. Hoffman, A. S. \& Stayton, P. S. Conjugates of stimuliresponsive polymers and proteins. Prog. Polym. Sci. 32, 922-932 (2007).

55. Chapman, A. P. PEGylated antibodies and antibody fragments for improved therapy: a review. Adv. Drug Delivery Rev. 54, 531-545 (2002).

56. Caliceti, P. \& Veronese, F. M. Pharmacokinetic and biodistribution properties of poly (ethylene glycol)protein conjugates. Adv. Drug Delivery Rev. 55 1261-1277 (2003)

57. Alley, S. C., Okeley, N. M. \& Senter, P. D. Antibodydrug conjugates: targeted drug delivery for cancer. Curr. Opin. Chem. Biol. 14, 529-537 (2010).

58. Sievers, E. L. \& Senter, P. D. Antibody-drug conjugates in cancer therapy. Annu. Rev. Med. 64 15-29 (2013).

59. Proksch, E., Brandner, J. M. \& Jensen, J. M. The skin: an indispensable barrier. Exp. Dermatol. 17, 1063-1072 (2008).

This is a thorough Review summarizing the excellent barrier properties of the skin.

60. Naik, A., Kalia, Y. N. \& Guy, R. H. Transdermal drug delivery: overcoming the skin's barrier function. Pharm. Sci. Technol. Today 3, 318-326 (2000).

61. Prausnitz, M. R., Mitragotri, S. \& Langer, R. Current status and future potential of transdermal drug delivery. Nat. Rev. Drug Discov. 3, 115-124 (2004) This is a past overview of the status of transdermal delivery technologies up to 2004.

62. Prausnitz, M. R. \& Langer, R. Transdermal drug delivery. Nat. Biotechnol. 26, 1261 (2008).

63. Hansen, S. et al. The role of corneocytes in skin transport revised-a combined computational and experimental approach. Pharm. Res. 26, 1379-1397 (2009).

64. Bergstresser, P. R. \& Taylor, J. R. Epidermal 'turnover time' - a new examination. Br. J. Dermatol. 96 503-506 (1977)

65. Bouwstra, J. A \& Ponec, M. The skin barrier in healthy and diseased state. Biochim. Biophys. Acta 1758, 2080-2095 (2006)

66. Schoellhammer, C. M., Blankschtein, D. \& Langer, R. Skin permeabilization for transdermal drug delivery: recent advances and future prospects. Expert Opin. Drug Delivery 11, 393-407 (2014).

67. Benson, H. A. Transdermal drug delivery: penetration enhancement techniques. Curr. Drug Delivery 2 23-33 (2005).

This is a summary of formulation-based approaches to enhance the penetration of drugs across the skin.

68. Arora, A., Prausnitz, M. R. \& Mitragotri, S. Micro-scale devices for transdermal drug delivery. Int. J. Pharmaceut. 364, 227-236 (2008).

69. Sinha, V. \& Kaur, M. P. Permeation enhancers for transdermal drug delivery. Drug Dev. Industrial Pharmacy 26, 1131-1140 (2000).

70. Williams, A. C. \& Barry, B. W. Penetration enhancers. Adv. Drug Delivery Rev. 64, 128-137 (2012).

71. Pillai, O. \& Panchagnula, R. Transdermal delivery of insulin from poloxamer gel: ex vivo and in vivo skin permeation studies in rat using iontophoresis and chemical enhancers. J. Control. Release 89, 127-140 (2003).

72. Karande, P. \& Mitragotri, S. Enhancement of transdermal drug delivery via synergistic action of chemicals. Biochim. Biophys. Acta 1788, 2362-2373 (2009).

73. Mitragotri, S., Blankschtein, D. \& Langer, R Ultrasound-mediated transdermal protein delivery. Science 269, 850-853 (1995)

74. Mitragotri, S. Healing sound: the use of ultrasound in drug delivery and other therapeutic applications. Nat. Rev. Drug Discov. 4, 255 (2005).

75. Chien, Y., Siddiqui, O., Sun, Y., Shi, W. \& Liu, J. Transdermal iontophoretic delivery of therapeutic peptides/proteins I: insulin. Ann. NY Acad. Sci. 507, 32-51 (1987).

76. Prausnitz, M. R. A practical assessment of transdermal drug delivery by skin electroporation. Adv. Drug Delivery Rev. 35, 61-76 (1999).
77. Prausnitz, M. R. Microneedles for transdermal drug delivery. Adv. Drug Delivery Rev. 56, 581-587 (2004).

78. Henry, S., McAllister, D. V., Allen, M. G. \& Prausnitz, M. R. Microfabricated microneedles: a novel approach to transdermal drug delivery. J. Pharm. Sci. 87, 922-925 (1998).

79. Kim, Y.-C., Park, J.-H. \& Prausnitz, M. R. Microneedles for drug and vaccine delivery. Adv. Drug Delivery Rev. 64, 1547-1568 (2012)

80. Mitragotri, S. Current status and future prospects of needle-free liquid jet injectors. Nat. Rev. Drug Discov. 5, 543 (2006)

81. Morales, J. O. et al. Challenges and future prospects for the delivery of biologics: oral mucosal, pulmonary, and transdermal routes. AAPS J. 19, 652-668 (2017).

82. Gill, H. S., Denson, D. D., Burris, B. A. \& Prausnitz, M. R. Effect of microneedle design on pain in human subjects. Clin. J. Pain 24, 585 (2008).

83. Park, J.-H., Allen, M. G. \& Prausnitz, M. R. Polymer microneedles for controlled-release drug delivery. Pharm. Res. 23, 1008-1019 (2006).

84. Matsuzaki, K. Magainins as paradigm for the mode of action of pore forming polypeptides. Biochim. Biophys. Acta 1376, 391-400 (1998).

85. Kim, Y.-C., Ludovice, P. J. \& Prausnitz, M. R. Transdermal delivery enhanced by magainin poreforming peptide. J. Control. Release 122, 375-383 (2007).

86. Nasrollahi, S. A., Taghibiglou, C., Azizi, E. \& Farboud, E. S. Cell-penetrating peptides as a novel transdermal drug delivery system. Chem. Biol. Drug Design 80, 639-646 (2012).

87. Chen, Y. et al. Transdermal protein delivery by a coadministered peptide identified via phage display. Nat. Biotechnol. 24, 455 (2006)

88. Hsu, T. \& Mitragotri, S. Delivery of siRNA and other macromolecules into skin and cells using a peptide enhancer. Proc. Natl Acad. Sci. 108, 15816-15821 (2011)

89. Lopes, L. B. et al. Comparative study of the skin penetration of protein transduction domains and a conjugated peptide. Pharm. Res. 22, 750-757 (2005).

90. Desai, P., Patlolla, R. R. \& Singh, M. Interaction of nanoparticles and cell-penetrating peptides with skin for transdermal drug delivery. Mol. Membrane Biol. 27, 247-259 (2010).

91. Chen, M. et al. Topical delivery of siRNA into skin using SPACE-peptide carriers. J. Control. Release 179 33-41 (2014)

92. Menegatti, S. et al. De novo design of skin penetrating peptides for enhanced transdermal delivery of peptide drugs. Adv. Healthcare Mater. $\mathbf{5}$. 602-609 (2016)

93. J. Yu et al. Microneedle-array patches loaded with hypoxia-sensitive vesicles provide fast glucoseresponsive insulin delivery. Proc. Natl Acad. Sci. 112, 8260-8265 (2015).

This is a recent preclinical paper describing stimuli-responsive microneedles for transdermal insulin delivery.

94. Y. Ye et al. Microneedles integrated with pancreatic cells and synthetic glucose-signal amplifiers for smart insulin delivery. Adv. Mater. 28, 3115-3121 (2016).

95. Y. Ye et al. A melanin-mediated cancer immunotherapy patch. Sci. Immunol. 2, eaan5692 (2017).

96. Moniruzzaman, M., Tahara, Y., Tamura, M., Kamiya, N. $\&$ Goto, M. lonic liquid-assisted transdermal delivery of sparingly soluble drugs. Chem. Commun. 46 1452-1454 (2010)

97. Agatemor, C., Ibsen, K. N., Tanner, E. E. \& Mitragotri, S. Ionic liquids for addressing unmet needs in healthcare. Bioeng. Transl Med. 3, 7-25 (2018).

98. Novotny, M. et al. Ammonium carbamates as highly active transdermal permeation enhancers with a dual mechanism of action. J. Control. Release 150, 164-170 (2011)

99. Kundu, N., Roy, S., Mukherjee, D., Maiti, T. K. \& Sarkar, N. Unveiling the interaction between fattyacid-modified membrane and hydrophilic imidazolium based ionic liquid: understanding the mechanism of ionic liquid cytotoxicity. J. Phys. Chem. B 121 , 8162-8170 (2017)

100. Banerjee, A., Ibsen, K., Iwao, Y., Zakrewsky, M. \& Mitragotri, S. Transdermal protein delivery using choline and geranate (CAGE) deep eutectic solvent. Adv. Healthc. Mater. https://doi.org/10.1002/ adhm.201601411 (2017). 
101. Goldberg, M. \& Gomez-Orellana, I. Challenges for the oral delivery of macromolecules. Nat. Rev. Drug Discov. 2, 289-295 (2003)

This is a detailed Review highlighting the potential of the oral delivery of biologics.

102. Nellans, H. N. (B) Mechanisms of peptide and protein absorption:(1) Paracellular intestinal transport: modulation of absorption. Adv. Drug Delivery Rev. 7, 339-364 (1991).

103. Burton, P. S., Conradi, R. A. \& Hilgers, A. R. (B) Mechanisms of peptide and protein absorption:(2) Transcellular mechanism of peptide and protein absorption: passive aspects. Adv. Drug Delivery Rev. 7, 365-385 (1991).

104. Tsuji, A. \& Tamai, I. Carrier-mediated intestinal transport of drugs. Pharm. Res. 13, 963-977 (1996).

105. Swaan, P. W. Recent advances in intestinal macromolecular drug delivery via receptor-mediated transport pathways. Pharm. Res. 15, 826-834 (1998).

106. Larhed, A. W., Artursson, P. \& Björk, E. The influence of intestinal mucus components on the diffusion of drugs. Pharm. Res. 15, 66-71 (1998).

107. Ensign, L. M., Cone, R. \& Hanes, J. Oral drug delivery with polymeric nanoparticles: the gastrointestinal mucus barriers. Adv. Drug Delivery Rev. 64, 557-570 (2012).

108. Cone, R. A. Barrier properties of mucus. Adv. Drug Delivery Rev. 61, 75-85 (2009).

109. Newby, J. et al. A blueprint for robust crosslinking of mobile species in biogels with weakly adhesive molecular anchors. Nat. Commun. 8, 833 (2017)

110. Davis, S., Hardy, J. \& Fara, J. Transit of pharmaceutical dosage forms through the small intestine. Gut 27, 886-892 (1986)

111. Carino, G. P. \& Mathiowitz, E. Oral insulin delivery. Adv. Drug Delivery Rev. 35, 249-257 (1999).

112. Morishita, M. \& Peppas, N. A. Is the oral route possible for peptide and protein drug delivery? Drug Discov. Today 11, 905-910 (2006).

113. Wilson, I. D. \& Nicholson, J. K. Gut microbiome interactions with drug metabolism, efficacy, and toxicity. Transl Res. 179, 204-222 (2017).

114. Kolars, J. C., Watkins, P., Merion, R. M. \& Awni, W. First-pass metabolism of cyclosporin by the gut. Lancet 338, 1488-1490 (1991).

115. Cole, E. T. et al. Enteric coated HPMC capsules designed to achieve intestinal targeting. Int. J. Pharmaceut. 231, 83-95 (2002)

116. Baumgartner, S., Kristl, J., Vrecer, F., Vodopivec, P. \& Zorko, B. Optimisation of floating matrix tablets and evaluation of their gastric residence time. Int. J. Pharmaceut. 195, 125-135 (2000).

117. Theeuwes, F. OROS ${ }^{\circledast}$ osmotic system development. Drug Dev. Industrial Pharmacy 9, 1331-1357 (1983).

118. Harrison, G. Insulin in alcoholic solution by the mouth Br. Med. J. 2, 1204 (1923).

This is one of the first published reports on improving the oral delivery of insulin via the use of absorption enhancers.

119. Muranishi, S. Absorption enhancers. Crit. Rev. Ther Drug Carrier Systems 7, 1-33 (1990).

120. Constantinides, P. P. Lipid microemulsions for improving drug dissolution and oral absorption: physical and biopharmaceutical aspects. Pharm. Res. 12, 1561-1572 (1995)

121. Whitehead, K. \& Mitragotri, S. Mechanistic analysis of chemical permeation enhancers for oral drug delivery. Pharm. Res. 25, 1412-1419 (2008).

122. Fasano, A. \& Uzzau, S. Modulation of intestinal tight junctions by Zonula occludens toxin permits enteral administration of insulin and other macromolecules in an animal model. J. Clin. Invest. 99, 1158-1164 (1997).

123. Thanou, M., Verhoef, J. \& Junginger, H. Oral drug absorption enhancement by chitosan and its derivatives. Adv. Drug Delivery Rev. 52, 117-126 (2001).

124. Jain, S., Kambam, S., Thanki, K. \& Jain, A. K. Cyclosporine A loaded self-nanoemulsifying drug delivery system (SNEDDS): implication of a functional excipient based co-encapsulation strategy on oral bioavailability and nephrotoxicity. RSC Adv. $\mathbf{5}$, 49633-49642 (2015).

125. Guada, M. et al. Reformulating cyclosporine A (CSA): more than just a life cycle management strategy. J. Control. Release 225, 269-282 (2016).

126. Ritschel, W. Microemulsion technology in the reformulation of cyclosporine: the reason behind the pharmacokinetic properties of Neoral. Clin. Transplant. 10, 364-373 (1996).
127. Gursoy, R. N. \& Benita, S. Self-emulsifying drug delivery systems (SEDDS) for improved oral delivery of lipophilic drugs. Biomed. Pharmacother. 58, 173-182 (2004).

128. Braat, $\mathrm{H}$. et al. A phase I trial with transgenic bacteria expressing interleukin-10 in Crohn's disease. Clin. Gastroenterol. Hepatol. 4, 754-759 (2006).

129. Brayden, D. J. \& Alonso, M.-J. Oral delivery of peptides: opportunities and issues for translation. Adv. Drug Deliv. Rev. 106, 193-195 (2016).

130. Traverso, G. et al. Microneedles for drug delivery via the gastrointestinal tract. J. Pharm. Sci. 104, 362-367 (2015).

131. Eaimtrakarn, S. et al. Retention and transit of intestinal mucoadhesive films in rat small intestine. Int. J. Pharmaceut. 224, 61-67 (2001).

132. Eiamtrakarn, S. et al. Gastrointestinal mucoadhesive patch system (GI-MAPS) for oral administration of G-CSF, a model protein. Biomaterials 23, 145-152 (2002)

133. Grabovac, V., Guggi, D. \& Bernkop-Schnürch, A. Comparison of the mucoadhesive properties of various polymers. Adv. Drug Delivery Rev. 57, 1713-1723 (2005).

134. Borchard, G. et al. The potential of mucoadhesive polymers in enhancing intestinal peptide drug absorption. III: Effects of chitosan-glutamate and carbomer on epithelial tight junctions in vitro. J. Control. Release 39, 131-138 (1996)

135. Lehr, C.-M., Bouwstra, J. A., Schacht, E. H. \& Junginger, $H$. E. In vitro evaluation of mucoadhesive properties of chitosan and some other natural polymers. Int. J. Pharmaceut. 78, 43-48 (1992).

136. Fujita, T. et al. Improvement of intestinal absorption of human calcitonin by chemical modification with fatty acids: synergistic effects of acylation and absorption enhancers. Int. J. Pharmaceut. 134, 47-57 (1996).

137. Aungst, B. J. Intestinal permeation enhancers. J. Pharm. Sci. 89, 429-442 (2000)

138. Whitehead, K., Karr, N. \& Mitragotri, S. Safe and effective permeation enhancers for oral drug delivery. Pharm. Res. 25, 1782-1788 (2008).

139. Matthews, D. Intestinal absorption of peptides. Physiol. Rev. 55, 537-608 (1975).

140. Pauletti, G. M. et al. Structural requirements for intestinal absorption of peptide drugs. J. Control. Release 41, 3-17 (1996).

141. Choonara, B. F. et al. A review of advanced oral drug delivery technologies facilitating the protection and absorption of protein and peptide molecules. Biotechnol. Adv. 32, 1269-1282 (2014).

142. Whitehead, K., Shen, Z. \& Mitragotri, S. Oral delivery of macromolecules using intestinal patches: applications for insulin delivery. J. Control. Release 98, 37-45 (2004)

143. Banerjee, A., Lee, J. \& Mitragotri, S. Intestinal mucoadhesive devices for oral delivery of insulin. Bioeng. Transl Med. 1, 338-346 (2016).

144. Gupta, V. et al. Delivery of exenatide and insulin using mucoadhesive intestinal devices. Ann. Biomed. Engineer. 44, 1993-2007 (2016).

145. He, H., Cao, X. \& Lee, L. J. Design of a novel hydrogelbased intelligent system for controlled drug release. J. Control. Release 95, 391-402 (2004).

146. Colombo, P. Swelling-controlled release in hydrogel matrices for oral route. Adv. Drug Delivery Rev. 11 37-57 (1993).

147. Lowman, A., Morishita, M., Kajita, M., Nagai, T. \& Peppas, N. Oral delivery of insulin using $\mathrm{pH}$-responsive complexation gels. J. Pharm. Sci. 88, 933-937 (1999).

148. Gupta, P., Vermani, K. \& Garg, S. Hydrogels: from controlled release to $\mathrm{pH}$-responsive drug delivery. Drug Discov. Today 7, 569-579 (2002).

149. Chirra, H. D. \& Desai, T. A. Emerging microtechnologies for the development of oral drug delivery devices. Adv. Drug Delivery Rev. 64, 1569-1578 (2012)

150. Chirra, H. D. \& Desai, T. A. Multi-reservoir bioadhesive microdevices for independent ratecontrolled delivery of multiple drugs. Small 8 3839-3846 (2012)

151. Tao, S. L. \& Desai, T. A. Gastrointestinal patch systems for oral drug delivery. Drug Discov. Today 10, 909-915 (2005).

152. Banerjee, A. et al. Ionic liquids for oral insulin delivery. Proc. Natl Acad. Sci. USA 115, 7296-7301 (2018).

153. Davis, M. E., Chen, Z. G. \& Shin, D. M. Nanoparticle therapeutics: an emerging treatment modality for cancer. Nat. Rev. Drug Discov. 7, 771-782 (2008).
154. Petros, R. A. \& DeSimone, J. M. Strategies in the design of nanoparticles for therapeutic applications. Nat. Rev. Drug Discov. 9, 615-627 (2010).

155. Hoffman, A. S. The origins and evolution of "controlled" drug delivery systems. J. Control. Release 132, 153-163 (2008)

156. Pridgen, E. M. et al. Transepithelial transport of Fc-targeted nanoparticles by the neonatal Fc receptor for oral delivery. Sci. Transl Med. 5, 213 ra 167 (2013).

This is a recent preclinical study that demonstrates the successful delivery of insulin via the oral delivery of targeted nanoparticles.

157. Yun, Y., Cho, Y. W. \& Park, K. Nanoparticles for oral delivery: targeted nanoparticles with peptidic ligands for oral protein delivery. Adv. Drug Delivery Rev. 65 , 822-832 (2013).

158. Fonseca, S. B., Pereira, M. P. \& Kelley, S. O. Recent advances in the use of cell-penetrating peptides for medical and biological applications. Adv. Drug Delivery Rev. 61, 953-964 (2009).

159. Farokhzad, O. C. et al. Nanoparticle-aptamer bioconjugates: a new approach for targeting prostate cancer cells. Cancer Res. 64, 7668-7672 (2004).

160. Bannunah, A. M., Vllasaliu, D., Lord, J. \& Stolnik, S Mechanisms of nanoparticle internalization and transport across an intestinal epithelial cell model: effect of size and surface charge. Mol. Pharmaceut. 11, 4363-4373 (2014)

161. Lai, S. K., Wang, Y.-Y. \& Hanes, J. Mucus-penetrating nanoparticles for drug and gene delivery to mucosal tissues. Adv. Drug Delivery Rev. 61, 158-171 (2009).

162. Lai, S. K. et al. Rapid transport of large polymeric nanoparticles in fresh undiluted human mucus. Proc. Natl Acad. Sci. 104, 1482-1487 (2007).

163. Wang, Y. Y. et al. Addressing the PEG mucoadhesivity paradox to engineer nanoparticles that "slip" through the human mucus barrier. Angew. Chem. Int. Ed. Engl. 47, 9726-9729 (2008)

164. Anselmo, A. C. \& Mitragotri, S. Nanoparticles in the clinic. Bioeng. Trans/ Med. 1, 10-29 (2016).

165. Holmgren, J. \& Czerkinsky, C. Mucosal immunity and vaccines. Nat. Med. 11, S45 (2005)

166. Yamamoto, A. et al. Effects of various protease inhibitors on the intestinal absorption and degradation of insulin in rats. Pharm. Res. 11, 1496-1500 (1994)

167. Lee, V. H. \& Yamamoto, A. Penetration and enzymatic barriers to peptide and protein absorption. Adv. Drug Delivery Rev. 4, 171-207 (1989).

168. Aguirre, T. A. et al. Current status of selected oral peptide technologies in advanced preclinical development and in clinical trials. Adv. Drug Delivery Rev. 106, 223-241 (2016).

169. Riglar, D. T. \& Silver, P. A. Engineering bacteria for diagnostic and therapeutic applications. Nat. Rev. Microbiol. 16, 214-225 (2018).

170. Patton, J. S. \& Byron, P. R. Inhaling medicines: delivering drugs to the body through the lungs Nat. Rev. Drug Discov. 6, 67 (2007).

This is a Review of advances in the systemic delivery of small molecules and biologics via inhalation. This Review further highlights aspects of lung physiology that affect systemic absorption.

171. Bosquillon, C., Lombry, C., Preat, V. \& Vanbever, R. Influence of formulation excipients and physical characteristics of inhalation dry powders on their aerosolization performance. J. Control. Release $\mathbf{7 0}$ 329-339 (2001)

172. Yang, W., Peters, J. I., Williams, I. I. I., R. O. Inhaled nanoparticles - a current review. Int. J. Pharmaceut. 356, 239-247 (2008).

173. Van Golde, L., Batenburg, J. J. \& Robertson, B. The pulmonary surfactant system: biochemical aspects and functional significance. Physiol. Rev. 68, 374-455 (1988)

174. Labiris, N. \& Dolovich, M. Pulmonary drug delivery. Part I: physiological factors affecting therapeutic effectiveness of aerosolized medications. Br. J. Clin. Pharmacol. 56, 588-599 (2003).

175. van Iwaarden, F., Welmers, B., Verhoef, J., Haagsman, H. P. \& Van Golde, L. Pulmonary surfactant protein A enhances the host-defense mechanism of rat alveolar macrophages. Am. J. Respir. Cell. Mol. Biol. 2 91-98 (1990)

176. Geller, D. E. Comparing clinical features of the nebulizer, metered-dose inhaler, and dry powder inhaler. Respiratory Care 50, 1313-1322 (2005)

177. Dalby, R. \& Suman, J. Inhalation therapy: technological milestones in asthma treatment. Adv. Drug Delivery Rev. 55, 779-791 (2003). 
178. Anderson, P. J. History of aerosol therapy: liquid nebulization to MDIs to DPIs. Respiratory Care $\mathbf{5 0}$ 1139-1150 (2005)

179. Telko, M. J. \& Hickey, A. J. Dry powder inhaler formulation. Respiratory Care 50, 1209-1227 (2005).

180. Edwards, D. A. et al. Large porous particles for pulmonary drug delivery. Science 276, 1868-1872 (1997).

181. Shoyele, S. A. \& Cawthorne, S. Particle engineering techniques for inhaled biopharmaceuticals. Adv. Drug Delivery Rev. 58, 1009-1029 (2006).

182. Vanbever, R. et al. Formulation and physical characterization of large porous particles for inhalation. Pharm. Res. 16, 1735-1742 (1999).

183. French, D. L., Edwards, D. A. \& Niven, R. W. The influence of formulation on emission, deaggregation and deposition of dry powders for inhalation. J. Aerosol Sci. 27, 769-783 (1996).

184. Edwards, D. A., Ben-Jebria, A. \& Langer, R. Recent advances in pulmonary drug delivery using large, porous inhaled particles. J. Appl. Physiol. 85, 379-385 (1998).

185. Hickey, A. J. Pharmaceutical Inhalation Aerosol Technology (CRC Press, 2003).

186. Hickey, A. J. Inhalation Aerosols: Physical and Biological Basis for Therapy (CRC Press, 1996).

187. Al, M. M.-Tabakha, Future prospect of insulin inhalation for diabetic patients: The case of Afrezza versus Exubera. J. Control. Release 215, 25-38 (2015).

188. White, S. et al. EXUBERA*: pharmaceutical development of a novel product for pulmonary delivery of insulin. Diabetes Technol. Ther. 7, 896-906 (2005)

189. Hollander, P. A. et al. Efficacy and safety of inhaled insulin (Exubera) compared with subcutaneous insulin therapy in patients with type 2 diabetes: results of a 6-month, randomized, comparative trial. Diabetes Care 27, 2356-2362 (2004).

190. Rosenstock, J., Cappelleri, J. C., Bolinder, B. \& Gerber, R. A. Patient satisfaction and glycemic control after 1 year with inhaled insulin (Exubera) in patients with type 1 or type 2 diabetes. Diabetes Care 27 , 1318-1323 (2004).

191. Skyler, J. S., Jovanovic, L., Klioze, S., Reis, J. \& Duggan, W. Two-year safety and efficacy of inhaled human insulin (Exubera) in adult patients with type 1 diabetes. Diabetes Care 30, 579-585 (2007).

192. Hickey, A. J. Back to the future: inhaled drug products. J. Pharm. Sci. 102, 1165-1172 (2013).

193. Heinemann, L. The failure of Exubera: are we beating a dead horse? J. Diabetes Sci. Technol. 2, 518-529 (2008).

194. Mitri, J. \& Pittas, A. G. Inhaled insulin - what went wrong. Nat. Clin. Pract. Endocrinol. 5, 24 (2008).

195. Sélam, J.-L. Inhaled insulin: promises and concerns. J. Diabetes Sci. Technol. 2, 311-315 (2008).

196. Forst, T. et al. Time-action profile and patient assessment of inhaled insulin via the Exubera device in comparison with subcutaneously injected insulin aspart via the FlexPen device. Diabetes Technol. Ther 11, 87-92 (2009).
197. Cavaiola, T. S. \& Edelman, S. Inhaled insulin: a breath of fresh air? A review of inhaled insulin. Clin. Ther. 36, 1275-1289 (2014).

198. Kling, J. Sanofi to propel inhalable insulin Afrezza into market. Nat. Biotechnol. 32, 851-852 (2014).

199. Halliday, H. L. Surfactant replacement therapy. Pediatr. Pulmonol. 19, 96-97 (1995).

200. Liang, Z., Ni, R., Zhou, J. \& Mao, S. Recent advances in controlled pulmonary drug delivery. Drug Discov. Today 20, 380-389 (2015).

201. Ruge, C. A., Kirch, J. \& Lehr, C.-M. Pulmonary drug delivery: from generating aerosols to overcoming biological barriers-therapeutic possibilities and technological challenges. Lancet Respir. Med. 1 402-413 (2013).

202. Kobayashi, S., Kondo, S. \& Juni, K. Pulmonary delivery of salmon calcitonin dry powders containing absorption enhancers in rats. Pharm. Res. 13, 80-83 (1996).

203. Moschos, S. A. et al. Lung delivery studies using siRNA conjugated to TAT (48-60) and penetratin reveal peptide induced reduction in gene expression and induction of innate immunity. Bioconjugate Chem. 18, 1450-1459 (2007)

204. Hussain, A., Arnold, J. J., Khan, M. A. \& Ahsan, F Absorption enhancers in pulmonary protein delivery. J. Control. Release 94, 15-24 (2004).

205. Illum, L. Nasal drug delivery - possibilities, problems and solutions. J. Control. Release 87, 187-198 (2003).

This is an outstanding Review summarizing the challenges with nasal drug delivery and potential strategies to overcome these challenges for biologics.

206. Caon, T., Jin, L., Simões, C. M., Norton, R. S. \& Nicolazzo, J. A. Enhancing the buccal mucosal delivery of peptide and protein therapeutics. Pharm. Res. 32 , 1-21 (2015)

207. Gandhi, R. B. $\&$ Robinson, J. R. Oral cavity as a site for bioadhesive drug delivery. Adv. Drug Delivery Rev. 13 43-74 (1994).

208. Hussain, M. A., Aungst, B. J., Koval, C. A. \& Shefter, E. Improved buccal delivery of opioid analgesics and antagonists with bitterless prodrugs. Pharm. Res. 5 615-618 (1988)

209. Shojaei, A. H. Buccal mucosa as a route for systemic drug delivery: a review. J. Pharm. Pharm. Sci. 1 , 15-30 (1998).

210. Zhou, X. H. Overcoming enzymatic and absorption barriers to non-parenterally administered protein and peptide drugs. J. Control. Release 29, 239-252 (1994).

211. Klatt, N. R. et al. Vaginal bacteria modify HIV tenofovir microbicide efficacy in African women. Science 356, 938-945 (2017).

212. Ugwoke, M. I., Verbeke, N. \& Kinget, R. The biopharmaceutical aspects of nasal mucoadhesive drug delivery. J. Pharmacy Pharmacol. 53, 3-22 (2001).

213. Rapoport, A. \& Winner, P. Nasal delivery of antimigraine drugs: clinical rationale and evidence base. Headache 46, S192-S201 (2006).
214. Senel, S. \& Hıncal, A. A. Drug permeation enhancement via buccal route: possibilities and limitations. J. Control. Release 72, 133-144 (2001).

215. Arora, P., Sharma, S. \& Garg, S. Permeability issues in nasal drug delivery. Drug Discov. Today 7 967-975 (2002)

216. Nicolazzo, J. A., Reed, B. L. \& Finnin, B. C. Buccal penetration enhancers - how do they really work? J. Control. Release 105, 1-15 (2005).

217. Rossi, S., Sandri, G. \& Caramella, C. M. Buccal drug delivery: a challenge already won? Drug Discov. Today Technol. 2, 59-65 (2005)

218. Boddupalli, B. M., Mohammed, Z. N., Nath, R. A. \& Banji, D. Mucoadhesive drug delivery system: an overview. J. Adv. Pharm. Technol. Res. 1, 381 (2010).

219. Montenegro-Nicolini, M. \& Morales, J. O. Overview and future potential of buccal mucoadhesive films as drug delivery systems for biologics. AAPS PharmSciTech 18, 3-14 (2017).

220. Morales, J. O. \& Brayden, D. J. Buccal delivery of small molecules and biologics: of mucoadhesive polymers, films, and nanoparticles. Curr. Opin. Pharmacol. 36, 22-28 (2017).

221. Thorne, R., Pronk, G., Padmanabhan, V. \& Frey li, W. Delivery of insulin-like growth factor-I to the rat brain and spinal cord along olfactory and trigeminal pathways following intranasal administration. Neuroscience 127, 481-496 (2004).

222. Thorne, R. G. et al. Quantitative analysis of the olfactory pathway for drug delivery to the brain. Brain Res. 692, 278-282 (1995).

Acknowledgements

S.M. acknowledges support from the National Institutes of Health, Grant R01DK097379.

\section{Competing interests}

S.M. is a shareholder of, consultant to and recipient of research grants from several drug delivery, pharmaceutical and biotechnology companies, including those active in the general area of research discussed in this article. The authors are inventors on several patents in the field of drug delivery and formulations that are owned by their current or former employers. The views presented here should not be considered as endorsements of any specific product or company.

\section{Publisher's note}

Springer Nature remains neutral with regard to jurisdictional claims in published maps and institutional affiliations.

Supplementary information

Supplementary information is available for this paper at https://doi.org/10.1038/nrd.2018.183.

\section{RELATED LINKS}

ClinicalTrials.gov: https://clinicaltrials.gov/

ALL LINKS ARE ACTIVE IN THE ONLINE PDF 